\title{
Development of Glycinergic and Glutamatergic Synaptic Transmission in the Auditory Brainstem of Perinatal Rats
}

\author{
Karl Kandler and Eckhard Friaufa \\ Department of Animal Physiology, University of Tübingen, D-72076 Tübingen, Germany
}

In contrast to our knowledge about the anatomical development of the mammalian central auditory system, the development of its physiological properties is still poorly understood. In order to better understand the physiological properties of the developing mammalian auditory brainstem, we made intracellular recordings in brainstem slices from perinatal rats to examine synaptic transmission in the superior olivary complex, the first binaural station in the ascending auditory pathway. We concentrated on neurons in the lateral superior olive (LSO), which in adults, are excited from the ipsilateral side and inhibited from the contralateral side. Already at embryonic day (E) 18 , when axon collaterals begin to invade the LSO anlage, synaptic potentials could be evoked from ipsilateral, as well as from contralateral inputs. Ipsilaterally elicited PSPs were always depolarizing, regardless of age. They had a positive reversal potential and could be completely blocked by the nonNMDA glutamate receptor antagonist CNQX. In contrast, contralaterally elicited PSPs were depolarizing from E18P4, yet they turned into "adult-like," hyperpolarizing PSPs after P8. Their reversal potential shifted dramatically from $-21.6 \pm 17.7 \mathrm{mV}$ (E18-P0) to $-73.0 \pm 7.1 \mathrm{mV}$ (P10). Regardless of their polarity, contralaterally elicited PSPs were reversibly blocked by the glycine receptor antagonist strychnine. Bath application of glycine and its agonist $\beta$-alanine further confirmed the transitory depolarizing action of glycine in the auditory brainstem. Since the transient excitatory behavior of glycine occurs during a period during which glycinergic synaptic connections in the LSO aro refined by activity-dependent mechanisms, glycinergic excitation might be a mechanism by which synaptic rearrangement in the contralateral inhibitory pathway is accomplished.

[Key words: auditory, development, glutamate, glycine, inhibitory glycine receptor, lateral superior olive, rat, superior olivary complex, strychnine]

\footnotetext{
Received Mar. 31, 1995; revised June 12, 1995; accepted June 19, 1995.

We thank Dr. Donata Oertel for technical advice, Drs. Richard Mooney and Ellen Covey for helpful comments on an earlier version of the manuscript, and Dinnie-Ma Goldring for correcting our English. This work was supported by grants from the Deutsche Forschungsgemeinschaft to E.F. (Fr 772/1-2 and Fr772/1-3) and by fellowships from the Graduiertenkolleg Neurobiologie 'I'übingen and the DAAD/NATO to K.K.

Correspondence should be addressed to Karl Kandler, Ph.D., Department of Neurobiology, Box 3209, Duke Universily Medical Center, Durham, NC 27710.

aPresent address: Zentrum der Physiologie, University of Frankfurt, D-60590 Frankfurt, Germany.

Copyright (C) 1995 Society for Neuroscience 0270-6474/95/156890-15\$05.00/0
}

In contrast to our detailed knowledge of the development of excitatory connections in the CNS (review, Goodman and Shatz, 1993), relatively little is known about the development of inhibitory connections. This is due to the fact that inhibitory circuits are usually intrinsic to nuclei and formed by interneurons, and are therefore relatively inaccessible for analysis. The auditory brainstem of mammals, however, has proven to be a useful model for addressing the development of inhibitory connections (Sanes and Siverls, 1991; Sanes et al., 1992; Sanes, 1993; Sanes and Takacs, 1993), because inhibitory connections between auditory brainstem nuclei are highly topographically ordered and their adult anatomy and physiology are well documented (reviews, Irvine, 1992; Schwartz, 1992). The lateral superior olive (LSO), a nucleus in the superior olivary complex (SOC) that is involved in sound localization by processing binaural intensity differences, receives inhibitory, glycinergic input from the contralateral ear via the medial nucleus of the trapezoid body (MNTB), and excitatory, glutamatergic input from the ipsilateral ear via the ventral cochlear nucleus (see Fig. 1). Both inputs are tonotopically organized and perfectly aligned with each other (Caird and Klinke, 1983). During development, the contralateral glycinergic pathway is refined in part by pruning of the afferent glycinergic axon terminals of MNTB neurons within the LSO (Sanes and Siverls, 1991; Sanes and Takacs, 1993) as well as the postsynaptic dendritic trees of LSO neurons (Sanes and Chokshi, 1992; Sanes et al., 1992; Rietzel and Friauf, 1995). The morphological remodeling of the inhibitory pathway appears to be activity dependent, because remodeling is prevented by chronically blocking postsynaptic glycine receptors (Sanes and Chokshi, 1992) or by reducing neural activity in the MNTB (Moore, 1992; Sanes and Takacs, 1993). However, the cellular mechanisms underlying the activity-dependent remodeling of inhibitory synapses are completely unknown.

Innervation of the SOC begins at embryonic day (E) 18 (Kandler and Friauf, 1993a), but physiological hearing does not begin until the end of the second postnatal week (P12-14, e.g., Uziel et al., 1981). In the present study we used an in vitro brainstem slice preparation to examine the physiology and pharmacology of early synaptic transmission in the embryonic and postnatal SOC of rats during the period from E18 to the onset of hearing. We found that ipsilateral and contralateral synaptic transmission are both present as early as E18 and that the maturation of postsynaptic potentials (PSPs) in SOC neurons is marked by a decrease in their latency and duration. Most interestingly, however, we found that contralaterally elicited PSPs in LSO neurons reverse their polarity during development: in embryonic and early postnatal animals, the glycinergic strychnine-sensitive input is depolarizing, but in animals older than P8 it is hyperpolarizing. 


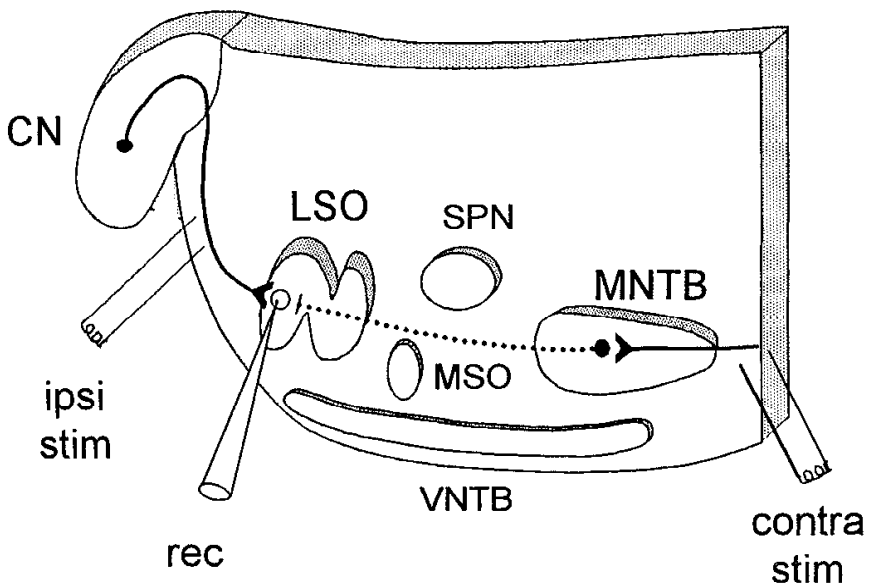

Figure 1. Schematic drawing of the auditory brainstem slice preparation illustrating the experimental design. Ipsilateral fibers from the cochlear nucleus $(C N)$ to the $S O C$ were electrically stimulated lateral to the lateral superior olive ( $L S O$ ) (ipsi stim) and contralateral fibers were stimulated at the midline (contra stim). Most intracellular recordings ( $\mathrm{rec}$ ) were obtained from LSO neurons, which receive excitatory, glutamatergic input (solid line) from the ipsilateral $\mathrm{CN}$ and inhibitory, glycinergic input (dashed line) from the contralateral $\mathrm{CN}$ via the medial nucleus of the trapezoid body (MNTB). Other nuclei of the SOC from which we obtained intracellular recordings are the medial superior olive (MSO), the ventral nucleus of the trapezoid body (VNTB), and the superior paraolivary nucleus $(S P N)$.

This is further supported by our finding that during the same period at which the contralateral input is depolarizing, bath-applied glycine has depolarizing effects in the SOC. We suggest that the depolarizing action of glycinc plays a rolc in activitydependent synaptic remodeling of the inhibitory pathway to the LSO, which occurs during early postnatal life.

Some of our data have been presented in abstract form (Kandler and Friauf, 1992, 1993b).

\section{Materials and Methods}

Animals. Experiments were performed on brainstem slices of embryonic (E18 to E21) and postnatal (P0 to P17) Sprague-Dawley rats of both genders. Animals were bred and housed in our own colony. Young adult rats were paired overnight and the first $24 \mathrm{hr}$ period following the commencement of pairing was considered E1. In order to account for variations in the gestational length (21-23 d), we equalized E22 with P0.

Brain slice preparation. Preparation of embryonic and postnatal brainstem slices was performed as described in detail elsewhere (Kandler and Friauf, 1993a). Timed-pregnant females were deeply anesthetized by intramuscular injections of a mixture of ketamine $(100 \mathrm{mg} / \mathrm{kg})$, xylazine $(2 \mathrm{mg} / \mathrm{kg})$, and chlorpromazine $(10 \mathrm{mg} / \mathrm{kg})$. Embryos were removed by Cesarean section and further anesthetized by hypothermia. Postnatal rat pups were anesthetized by ketamine $(100 \mathrm{mg} / \mathrm{kg}, \mathrm{i} . \mathrm{m}$.). Animals were decapitated and their brains were quickly removed and submerged in artificial cerebrospinal fluid (ACSF; composition in mM: $\mathrm{NaCl} 130.0, \mathrm{KCl} 3.0, \mathrm{NaH}_{2} \mathrm{PO}_{4} 1.2, \mathrm{CaCl}_{2} 2.4, \mathrm{MgSO}_{4} 1.3, \mathrm{NaHCO}_{3}$ 20, HEPES 3.0, glucose 10.0, bubbled with $95 \% \mathrm{O}_{2} / 5 \% \mathrm{CO}_{2}, \mathrm{pH} 7.4$, room temperature). Coronal slices $(400-500 \mu \mathrm{m}$ thick) were cut with a vibroslicer, and the slice that contained both the cochlear nuclei and the SOC was transferred to the recording chamber (submerged type, Medical. Systems), where it was continuously superfused with ACSF (30$33^{\circ} \mathrm{C}, 6-8 \mathrm{ml} / \mathrm{min}$, volume of recording chamber: $1.5 \mathrm{ml}$ ). Slices were allowed to recover for at least $90 \mathrm{~min}$ before electrophysiological recordings were started.

Electrophysiological recording and electrical stimulation. Intracellular recordings were made with glass micropipettes (150-250 M $\Omega$ ) filled with $2 \%$ biocytin (Sigma; Horikawa and Armstrong, 1988) or 4\% Neurobiotin (Vector; Kita and Armstrong, 1991) dissolved in $2 \mathrm{M} \mathrm{po-}$ tassium acetate. To improve the stability of the intracellular recordings, especially in young neurons, electrodes were silanized according to $\mathrm{Wu}$ and Oertel (1984). Penetration of neurons was achieved by applying short current or voltage pulses through the electrodes using the built-in circuits of the intracellular amplifier (Neurodata, Model 286). In a few cases, a weak negative current (holding current, -0.1 to $-0.3 \mathrm{nA}$ ) was applied for the first few minutes following the penetration in order to help stabilize the recording. Holding currents were always turned off before data gathering.

Synaptic responses were elicited by applying short current pulses $(60-80 \mu \mathrm{s}, 0.1-10 \mathrm{~mA}, 0.03-0.1 \mathrm{~Hz})$ to the ipsilateral or contralateral afferent fihers. Bipolar stainless steel electrodes (Rhodes NEX 200) were placed in the ventral acoustic stria (VAS), lateral to the SOC to activate the ipsilateral input and at the midline decussation, to activate the contralateral input (Fig. 1). To minimize current spread outside of the VAS, the two poles of each stimulation electrode were arranged perpendicular to the VAS, with the auditory fibers running between the two poles.

Pharmacological solutions. Concentrated stock solutions of the following drugs were prepared in distilled water, aliquoted, and stored at $-20^{\circ} \mathrm{C}$ : glycine, $\beta$-alanine, strychnine, kynurenic acid, 6-cyano-7-nitroquinoxaline-2,3-dione (CNQX), amino-5-phosphonovaleric acid (APV), (+)-5-methyl-10,11-dihydro-5H-dibenzo[a,d]cyclohepten-5,10-imine (MK801), and $\gamma$-aminobutyric acid (GABA). During the experiment, small amounts of stock solutions were added to the ACSF, resulting in the final dmg concentration in the recording chamber. Kynurenic acid was purchased from Fluka, CNQX, APV, and MK-801 were purchased from Research Biochemicals International, and the remaining chemicals from Sigma.

Data analysis. On-line analysis of intracellular signals was performed by digitizing ( $20-20,000 \mathrm{~Hz}$, AD-board from Batelle Europe) the output of the intracellular amplifier and by further processing with software (TIDA, Batelle Europe). Unprocessed signals were also stored on digital audiotape (DAT-recorder, Biologic, sampling rate $24 \mathrm{kHz}$ ) for later offline analysis.

PSPs were characterized by their latency, amplitude, half-width duration, and reversal potential. PSP latency was measured from the beginning of the stimulus artifact to the first noticeable deflection of the voltage trace from the baseline membrane potential. Spike latency was measured from the beginning of the stimulus artifact to the peak of the spike. Half-width duration was determined by measuring the PSP length at half maximum amplitude. PSP reversal potentials $\left(E_{\text {rev }} s\right)$ were determined by hyperpolarizing or depolarizing the neurons with current pulses ( 800 msec duration) during which the PSPs were elicited; the average amplitude of 5-10 PSPs at each membrane potential $\left(\mathrm{V}_{\mathrm{m}}\right)$ was plotted against $V_{m}$, and a linear regression analysis was used to determine $E_{r e v}$. Since high-resistance recording electrodes (150-250 M $\Omega$ ) were neccesary to obtain stable recordings, it was not always possible to perfectly bridge the electrode resistance when strong currents were injected. It is therefore possible that the actual membrane potential and $E_{\text {rev }}$ were somewhat closer to the resting potential than actually measured. Although this error might have influenced the absolute value of $\mathrm{E}_{\mathrm{rev}}$, it would not have influenced the observed developmental changes in $\mathrm{E}_{\mathrm{rev}}$ or the difference between ipsilateral and contralateral $E_{\mathrm{rev}} \mathrm{s}$ measured in the same neuron. Statistical significance was tested using linear regression analysis. Unless otherwise noted, data are presented as the arithmetic mean \pm standard deviation.

Intracellular staining. In order to unequivocally determine the type of neuron we recorded from, cells were intracellularly stained with biocytin or Neurobiotin, histochemically treated, and later morphologically analyzed. These procedures are described elsewhere (Kandler and Friauf, 1995).

\section{Results}

Our results are based on intracellular recordings from 115 neurons in 86 slices of perinatal rats, aged between E18 and P17. Neurons were located in varions nuclei of the SOC; since our emphasis was on neurons from the LSO, these neurons comprise the largest sample (55 neurons). The distribution of the remaining neurons was as follows: MNTB: 6; medial superior olive: 11 ; superior paraolivary nucleus: 8 ; lateral nucleus of the trapezoid body: 4; ventral nucleus of the trapezoid body: 10 ; dorsal periolivary nucleus: 2 ; rostral periolivary nucleus: 6 ; unidentified SOC neurons: 13. Due to the small number of neurons per nucleus, we will pool all SOC neurons outside the LSO into one 
A

E18

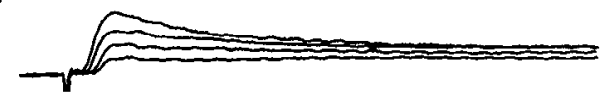

Sa

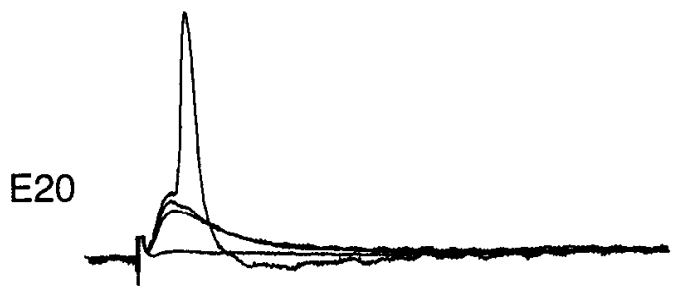

$20 \mathrm{mV}$

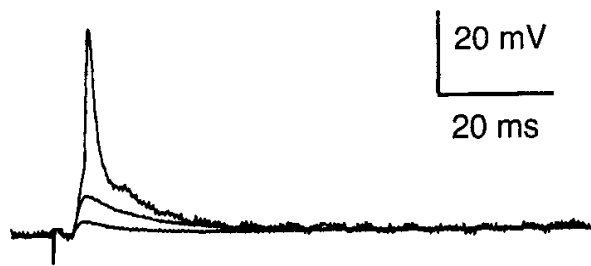

B

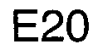

$\mathrm{P} 14$
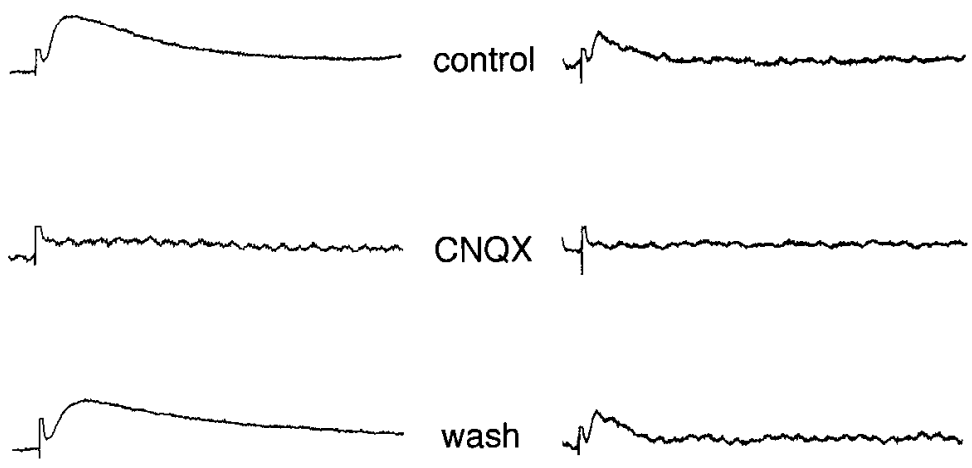

$5 \mathrm{mV}$

$20 \mathrm{~ms}$

Figure 2. Ipsilaterally elicited synaptic responses in perinatal LSO neurons. A, Examples of synaptic responses at different ages. Stimulation of the ipsilateral input elicited depolarizing PSPs whose amplitude increased with stimulus strength. These PSPs were always subthreshold at E18 (upper row). The first synaptically elicited action potentials occurred at E20 (middle row). $\mathrm{V}_{\text {rest }}:$ E18: $-68 \mathrm{mV}, E 20:-62 \mathrm{mV}, P 8:-64 \mathrm{mV}$. B, Pharmacology of ipsilaterally elicited synaptic responses. The non-NMDA antagonist CNQX completely and reversibly blocked ipsilaterally elicited depolarizing PSPs, E2O (left column) and P14 (right column) LSO neuron before (upper traces), during (middle traces), and 30 min after (lower traces) application of $20 \mu \mathrm{M}$ CNQX. $\mathrm{V}_{\text {rest }}: E 20:-62 \mathrm{mV}, P 14:-55 \mathrm{mV}$. Each trace is the average of three to five traces except for the traces with action potentials, which are single traces. $s a$ : stimulus artifact (truncated).

group called "remaining SOC neurons" and compare them to the "LSO neurons."

A typical intracellular recording lasted about $2 \mathrm{hr}$ (range 20 min to $9 \mathrm{hr}$ ). During this time, the quality of the recording and the health of each neuron were carefully observed by repeatedly measuring the membrane input resistance and the membrane time constant. If a spontaneous drop in these two values or in $\mathrm{V}_{\text {rest }}$ occurred, recordings were terminated.

The morphology and membrane properties (e.g., input resistance, resting membrane potential, discharge pattern) of these neurons were the subject of a previous report (Kandler and Friauf, 1995). The mean resting membrane potential $\left(\mathrm{V}_{\text {rest }}\right)$ of LSO neurons was $-59.1 \pm 6.1 \mathrm{mV}$ (range $-48 \mathrm{mV}$ to -70 $\mathrm{mV}$ ) and $\mathrm{V}_{\text {rest }}$ of the remaining SOC neurons was $-58.8 \pm 6.8$ $\mathrm{mV}$. Neither of these values changed in an age-dependent way.

\section{Development of synaptic responses in SOC neurons}

Synaptic responses were elicited by stimulating the ipsilateral or contralateral input fibers with single electrical pulses, laterally or medially to the SOC, respectively (Fig. 1). Sixty-six percent of the neurons (76 of 115) responded to ipsilateral stimulation and $81 \%$ (93 of 115 ) to contralateral stimulation. The onset latencies of the postsynaptic potentials (PSPs) varied between 1 and $17 \mathrm{~ms}$. Ninety-two percent of ipsilaterally elicited PSPs had latencies shorter than $5 \mathrm{msec}$, and $88 \%$ of contralaterally elicited PSPS had latencies shorter than $8 \mathrm{msec}$. These short latency PSPs were therefore most likely caused by electrical stimulation of auditory axons in the VAS (Sanes, 1990; Wu and Kelly, 1991). We will confine our analysis to these short-latency PSPs of presumptive auditory origin. In nine neurons, strong electrical stimulation elicited antidromic action potentials, which were characterized by a very constant latency and by the absence of preceding PSPs, even at a hyperpolarized membrane potential. Antidromic action potentials were thereforc clcarly distinguishable from synaptic responses and they were not included in subsequent analysis.

\section{Ipsilaterally elicited synaptic responses}

Already at E18, the age when cochlear nucleus axons have begun to invade the SOC (Kandler and Friauf, 1993a), ipsilateral stimulation elicited PSPs in SOC neurons $(n=5)$ with stimulusdependent graded amplitudes, suggesting the convergence of several afferent axons on a single SOC neuron (Fig. 2). At E18, depolarizing PSPs were always subthreshold, i.e., they never triggered postsynaptic action potentials despite the ability of the neurons to generate spikes when injected with depolarizing current (Kandler and Friauf, 1995). Synaptically elicited action potentials first occurred at E20 (Fig. 2). These spikes had the typical features of immature neurons in the SOC (Sanes, 1993; Kandler and Friauf, 1995) and in other parts of the ncrvous system (Spitzer, 1981; McCormick and Prince, 1987), i.e., they were of long duration and had a low peak amplitude.

Latency, duration, and reversal potential. The results from our quantitative analysis of latencies, amplitudes, and half-width durations of ipsilaterally elicited PSPs at various ages are summarized in Figure 3. In LSO neurons, the latencies of ipsilaterally elicited PSPs were in the range of 1.3 to $4.9 \mathrm{msec}$, and in the remaining SOC neurons, latencies were in the range of 1.0 
and $5.0 \mathrm{msec}$ (Fig. 3A). In both neuron groups, PSP latencies decreased significantly with age (LSO: $p<0.05$, SOC: $p<$ 0.01 ) from an average of $3.2 \mathrm{msec}$ at E18 to $1.3 \mathrm{msec}$ at P15. Ipsilaterally elicited PSPs could generate action potentials in $34 \%$ LSO neurons and $39 \%$ of remaining SOC neurons. Spike latencies decreased significantly with age in LSO neurons $(p<$ 0.01 , Fig. $3 B)$, but not in the remaining SOC neurons $(p>0.05)$. At the end of the second postnatal week, the time when hearing starts in rats, the latencies of ipsilaterally elicited PSPs in LSO neurons ranged from 1.3 to $2.2 \mathrm{msec}$, and the latencies of spikes ranged from 2.3 to $3.1 \mathrm{msec}$. These latencies are very similar to the PSP latencies reported for LSO neurons in other juvenile rodents [gerbil: $2.2 \mathrm{msec} \pm 0.3 \mathrm{SEM}$, (Sanes, 1990); mouse: $0.4-2.3 \mathrm{msec}$ (Wu and Kelly, 1991)], indicating that the velocity of ipsilateral transmission to the LSO is similar to that in mature animals at the onset of hearing.

In perinatal SOC neurons (E18-P9), the half-width duration of PSPs varied over a wide range (Fig. $3 C$ ). In LSO neurons, half-width durations were from 3.1 (P2) to $190 \mathrm{msec}$ (E20) and in the remaining SOC neurons from $6.8 \mathrm{msec}$ ( $\mathrm{P} 2$-neuron in the superior paraolivary nucleus) to $140 \mathrm{msec}$ (E20-neuron in the ventral nucleus of the trapezoid body). Although the longest EPSPs were recorded in embryonic animals, PSP half-width duration did not significantly decline with increasing age $(p>0.1)$. At the end of the second postnatal week, PSPs in LSO neurons had half-width durations of 4.2-5.2 msec, which are about twice as long as those reported from other young adult rodents (Sanes, 1990; Wu and Kelly, 1991). These long PSP durations imply that the accuracy of temporal integration in rat LSO neurons is still poor at the time of hearing onset, a situation similar to that described in young postnatal gerbils (Sanes, 1993).

In a previous study, we reported that the membrane time constant $(\tau)$ of SOC neurons significantly decreases during development (Kandler and Friauf, 1995). Since PSP duration is directly influenced by $\tau$, the observed decrease of PSP durations could simply be the result of decreasing $t$ values. As shown in Figure $3 D, \tau$ and PSP duration did covary in LSO neurons ( $p$ $<0.05$ ), but did not covary in the remaining SOC. neurons $(p$ $>0.05$ ). This indicates that the shortening of PSPs is at least partially caused by decreasing $t$ values in LSO neurons. The finding that $\tau$ and PSP duration did not covary in the remaining SOC neurons might simply be the result of pooling diverse neuron types from the different nuclei within this group. The reversal potentials $\left(\mathrm{E}_{\mathrm{rev}} \mathrm{s}\right)$ of ipsilaterally elicited PSPs were determined in 13 perinatal LSO neurons (E18-P10). The mean $\mathrm{E}_{\text {rev }}$ was $+19.8 \pm 21.4 \mathrm{mV}$, and we observed no age-dependent changes.

Pharmacology of ipsilaterally elicited PSPs. In adult mammals, the transmitter used by neurons in the cochlear nucleus that provide ipsilateral excitatory input to $\mathrm{SOC}$ neurons is most likely glutamate, acting on non-NMDA receptors (Caspary and Faingold, 1989; Caspary and Finlayson, 1991; Banks and Smith, 1992; Wu and Kelly, 1992). Recently, however, NMDA receptors have been identified immunohistochemically in the rat's LSO (Petralia et al., 1994) and NMDA receptor-mediated responses have been described in postnatal MNTB neurons using the whole-cell patch-clamp technique (Forsythe and Barnes-Davies, 1993). In order to characterize the transmitter and receptors involved in the early ipsilateral synaptic transmission to developing SOC neurons, we added the non-NMDA antagonist CNQX $(20 \mu \mathrm{M})$ into the bath solution and electrically activated the ipsilateral input. In all LSO neurons tested $(n=10)$, and in
8 out of 10 other SOC neurons, CNQX completely and reversibly blocked ipsilaterally elicited PSPs (Fig. $2 B$ ), suggesting that under our conditions $\left(\mathrm{V}_{\mathrm{m}}\right.$ at rest, $2.4 \mathrm{mM} \mathrm{Mg}{ }^{2+}$ in the bath solution), ipsilaterally elicited PSPs are caused by glutamate acting on postsynaptic non-NMDA receptors. It is therefore unlikely that the long PSPs, which often occurred in perinatal SOC neurons (Fig. $3 C$ ), were the result of long-lasting NMDA receptormediated responses.

Taken together, these data show that electrical stimulation of the ipsilateral input to the rat SOC already elicits synaptic responses at E18, which is around the time when ipsilateral axons are known to invade this region (Kandler and Friauf, 1993a). During the next 3 weeks, PSP latencies decrease significantly but there is no statistically significant decline in PSP duration. At the end of the second postnatal week, when hearing begins, PSP latencies are adult-like, but PSP durations are still about twice as long as in young adults (Sanes, 1990; Wu and Kelly, 1991). Our results further indicate that non-NMDA glutamate receptors mediate ipsilaterally elicited excitatory PSPs at all ages tested.

\section{Contralaterally elicited synaptic responses}

Three examples of contralaterally elicited PSPs in LSO neurons at different ages are shown in Figure 4. In embryonic and early postnatal LSO neurons (E18-P4; $n=34$ ), contralateral stimulation elicited depolarizing PSPS, not hyperpolarizing PSPs. In a few cases $(n=5)$ these depolarizing PSPs could trigger action potentials (Fig. 4A). Hyperpolarizing PSPs were first encountered at the end of the first postnatal week. In contrast to ipsilateral stimulation, which elicited spikes in $34 \%$ of LSO neurons, contralateral stimulation elicited spikes in only $14 \%$ of LSO neurons. No such difference was found in the remaining SOC neurons, in which spikes occurred with roughly the same frequency following both contralateral (36\%), and ipsilateral stimulation $(39 \%)$.

Latency, duration, and reversal potential. Results from our quantitative analysis of the latencies, amplitudes, and half-width durations of contralaterally elicited PSPs at various ages are shown in Figure 5. PSP latencies ranged from 1.5 to $7.1 \mathrm{msec}$ in LSO neurons and from 0.9 to $7.4 \mathrm{msec}$ in the remaining SOC neurons (Fig. 5A). In both groups, latencies decreased significantly with increasing age (LSO neurons: $p<0.05$; remaining SOC neurons: $p<0.01$ ). Latency reduction was more pronounced for contralaterally elicited PSPs than for ipsilaterally elicited PSPs, so that there was a gradual matching of the ipsilateral and contralateral transmission delays. For example, in embryonic LSO neurons, the latency difference between ipsiand contralaterally elicited PSPs averaged $1.9 \mathrm{msec}$ (ipsilateral: $2.9 \pm 0.9 \mathrm{~ms}, n=11$; contralateral: $4.8 \pm 1.7 \mathrm{msec}, n=8$ ). In animals at the end of the second postnatal week, however, the difference was only $0.5 \mathrm{msec}$ (ipsilateral: $2.3 \pm 0.8 \mathrm{msec}, n$ =8; contralateral: $2.8 \pm 1.0 \mathrm{msec}, n=8$ ). These results indicate that by the time hearing begins, converging ipsilateral and contralateral inputs arrive at LSO neurons almost simultaneously, which is a prerequisite for processing interaural intensity differences in the LSO.

As mentioned above, contralateral stimulation elicited spikes in only $14 \%$ ( 5 oul of 35 ) of LSO neurons. The peak latency of these spikes ranged from $13.0 \mathrm{msec}$ (E20) to $3.9 \mathrm{msec}$ (P8). Due to the small sampling size, age dependency was not statistically tested. In the remaining SOC neurons, synaptic spikes occurred 
LSO

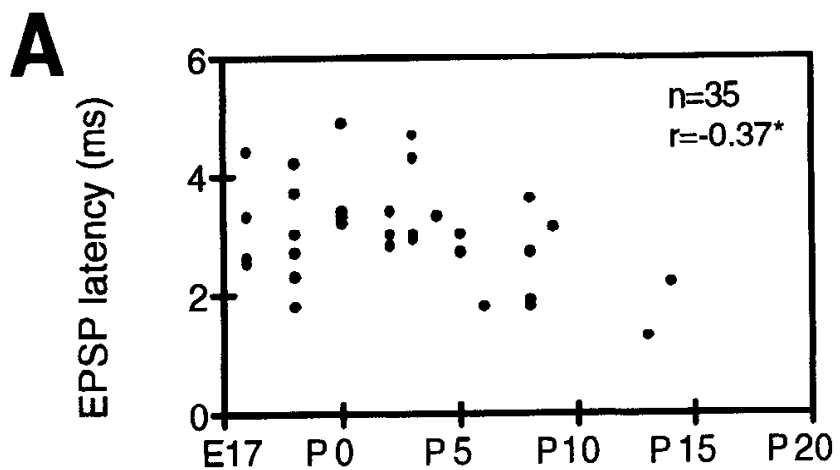

$B$ 足

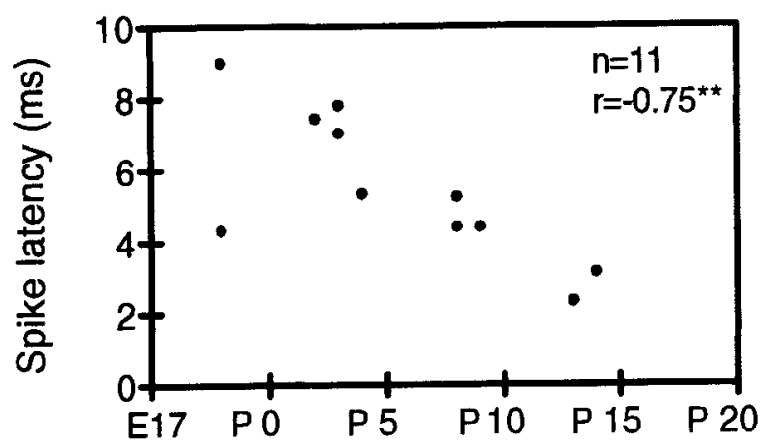

6

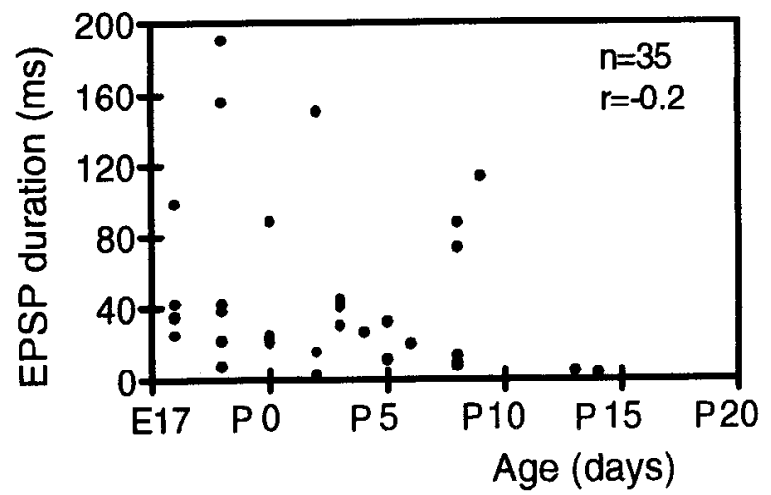

D

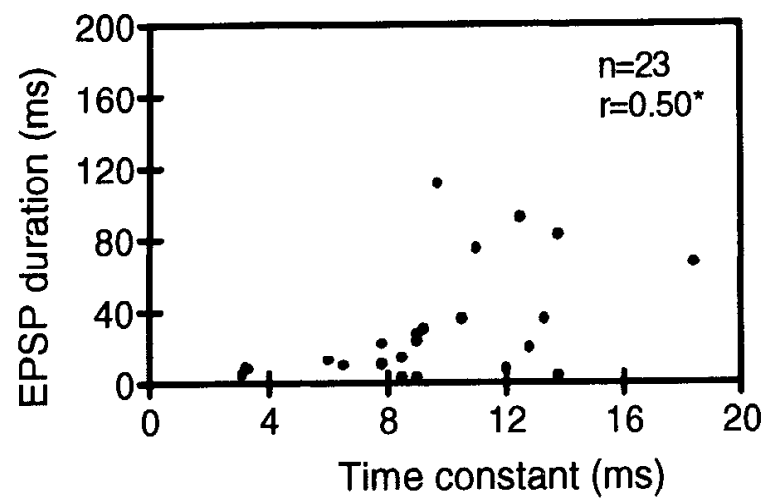

remaining SOC
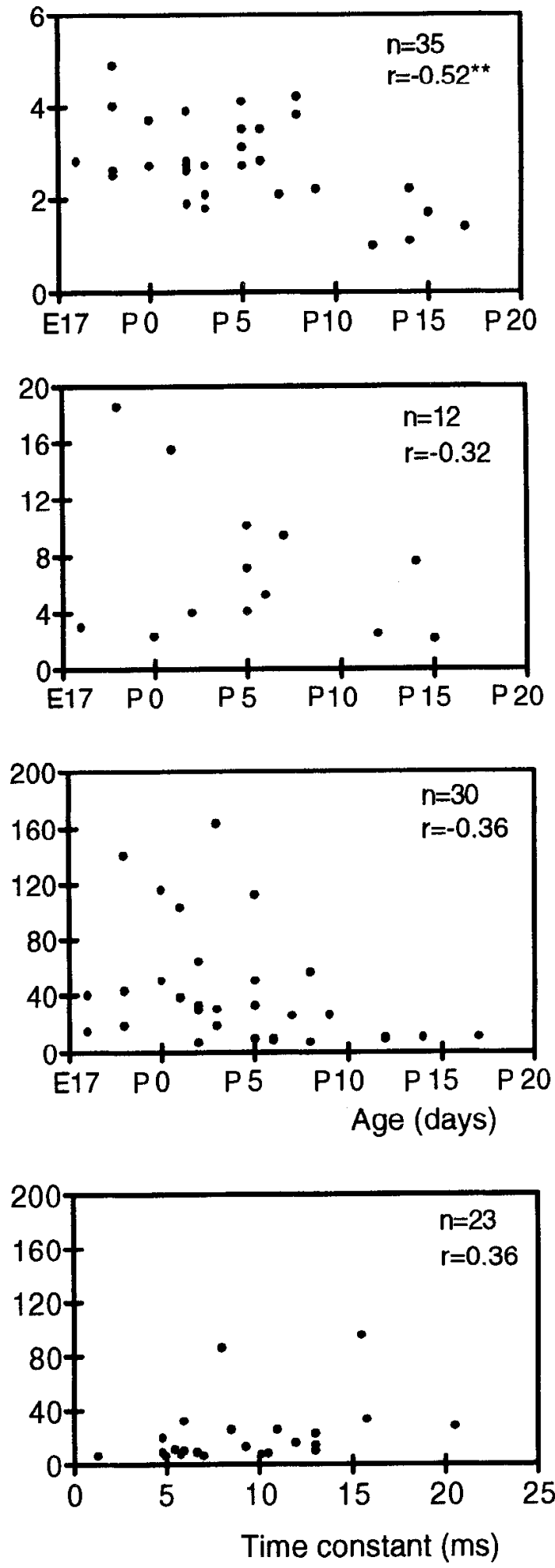

Figure 3. Quantitative analysis of ipsilaterally elicited PSPs in developing developing LSO neurons (left column) and in the remaining SOC neurons (right column). A, The latencies of ipsilaterally elicited PSPS decrease with age (LSO: $p<0.05 ;$ SOC: $p<0.01$ ). $B$, In LSO neurons, spike latencies decrease significantly with age $(p<0.01)$. No significant decrease was obvious in the remaining SOC neurons. $C$, The half-width duration of ipsilaterally elicited PSPS in both LSO neurons and other SOC neurons did not decrease significantly with age. $D$, PSP durations 
E18
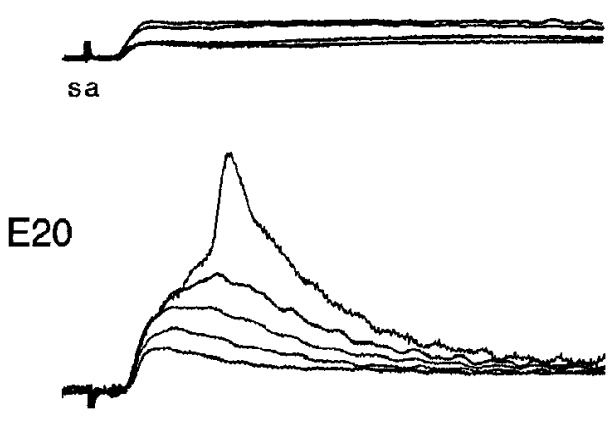

P8

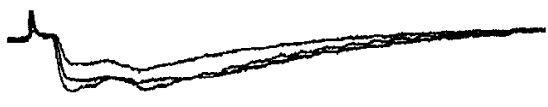

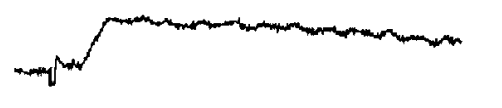
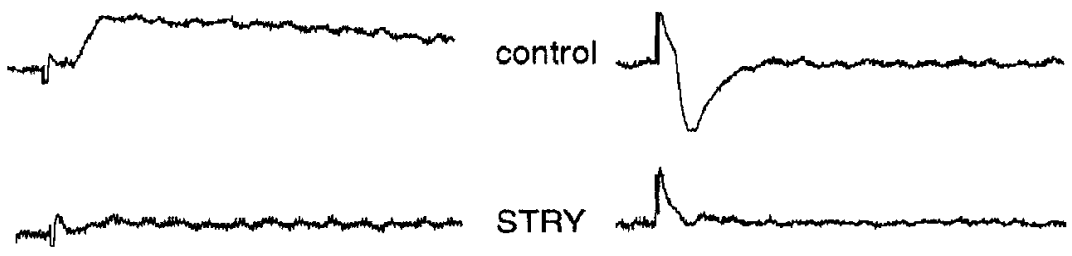

STRY

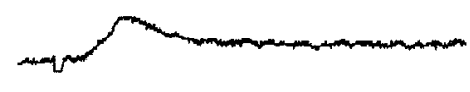

wash

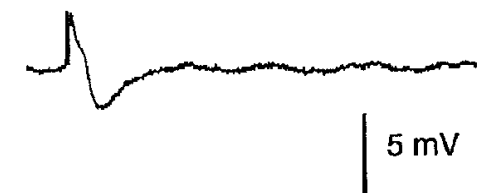

$20 \mathrm{~ms}$

$20 \mathrm{mV}$

$20 \mathrm{~ms}$

Figure 4. Contralaterally elicited synaptic responses in perinatal LSO neurons. A, Stimulation of the contralateral input elicited depolarizing PSPs at E18 and E20 (upper and middle row). From E20 on, these PSPs could sometimes trigger action potentials (middle row). "Adult-like," hyperpolarizing PSPs were elicited at P8 (lower row). $\mathrm{V}_{\text {rest }}: E 18:-68 \mathrm{mV}, E 20:-64 \mathrm{mV}, P 8:-70 \mathrm{mV}$. B, The glycine antagonist strychnine completely and reversibly blocked contralaterally elicited depolarizing PSPs at P0 and hyperpolarizing PSPs at P10. P0 (left column) and P10-LSO (right column) before (upper traces), during (middle traces), and 40 min after (lower traces) application of strychnine (P0: $10 \mu \mathrm{M}, \mathrm{P} 10: 1 \mu \mathrm{M})$. Each trace is the average of three to five consecutive single sweeps. $\mathrm{V}_{\text {resi }}: \mathrm{P0}:-58 \mathrm{mV}, \mathrm{P10}:-54 \mathrm{mV}$. sa: stimulus artifact (truncated).

in 15 out of 42 neurons, and the peak latency of these spikes decreased significantly during development $(p<0.05)$ (Fig. 5B).

The half-width duration of contralaterally elicited PSPs decreased considerably from E18 to P14, in both the LSO neurons and in the remaining SOC neurons (Fig. 5C). Despite this prominent decrease, at the end of the second postnatal week contralaterally elicited PSPs were still two to three times longer (P10P13: $10.2 \pm 7.6 \mathrm{msec}, n=3$ ) than those reported in young adult rodents [about 2-4 msec, see figures in Sanes (1990); and Wu and Kelly (1991)]. Half-width duration and $\tau$ of contralaterally elicited PSPs covaried significantly in LSO neurons $(p<0.01)$, but not in the remaining SOC neurons $(p>0.05)$, indicating that the change in duration of PSPs in LSO neurons is largely determined by the postsynaptic cells passive membrane properties.

The finding that contralateral stimulation elicited only depolarizing PSPs in perinatal LSO neurons is in sharp contrast to the situation seen in adult LSO neurons, where the contralateral glycinergic input is hyperpolarizing (Finlayson and Caspary, 1989; Wu and Kelly, 1992). Two obvious explanations could account for our findings: first, glycine could act transiently as a depolarizing transmitter or, second, contralateral afferent fibers in the LSO could temporarily release an excitatory transmitter during perinatal development. In a first step aimed at distinguish- ing between the two possibilities, we determined the $\mathrm{E}_{\text {rev }}$ of contralaterally elicited PSPs. In Figure 6, examples of contralaterally elicited PSPs at different $\mathrm{V}_{\mathrm{m}}$ are shown for a P10 neuron and a P3 neuron in the LSO. At $\mathrm{V}_{\text {rest }}(-57 \mathrm{mV})$, the P10 neuron responded to contralateral stimulation with hyperpolarizing PSPs. The amplitudes of these PSPs increased at more positive membrane potentials, whereas they decreased at more negative membrane potentials. Hyperpolarizing the membrane potential beyond $-78 \mathrm{mV}$ resulted in the reversal of PSP polarity, i.e., depolarizing PSPs were elicited at membrane potentials more negative than $-78 \mathrm{mV}$ (Fig. $6 \mathrm{C}$ ). In contrast to the neuron at $\mathrm{P} 10$, the $\mathrm{P} 3$ neuron responded at $\mathrm{V}_{\text {rest }}(-65 \mathrm{mV})$ to contralateral stimulation with depolarizing PSPs (Fig. 6B), and the PSPs reversed above $-30 \mathrm{mV}$, resulting in hyperpolarizing PSPs at these relatively positive membrane potentials (Fig. $6 B, D$ ). Figure 7 summarizes the $\mathrm{E}_{\mathrm{rev}}$ of contralaterally elicited PSPs in developing LSO neurons $(n=25)$ as a function of age. The average reversal potential of contralaterally elicited PSPs gradually shifted from $-21.6 \pm 17.7 \mathrm{mV}$ in embryonic and newborn animals (E18-P0, $n=7)$ to an average of $-73.0 \mathrm{mV} \pm 7.1$ in $\mathrm{P} 10$ animals $(n=2)(p<0.001)$. On average, $\mathrm{E}_{\mathrm{rev}} \mathrm{s}$ became more negative than $V_{\text {rest }}$ after P8 and thus gave rise to "adult-like," hyperpolarizing potentials. It is important to point out that in contrast to the observed changes in $E_{\text {rev }}$ from E18 to P10, $V_{\text {rest }}$

$\leftarrow$

were correlated with the membrane time constants in LSO neurons $(p<0.05)$, but not in the remaining SOC neurons $(p>0.05)$. Values for time constants were taken from Kandler and Friauf (1995). 


\section{contra}

LSO

A

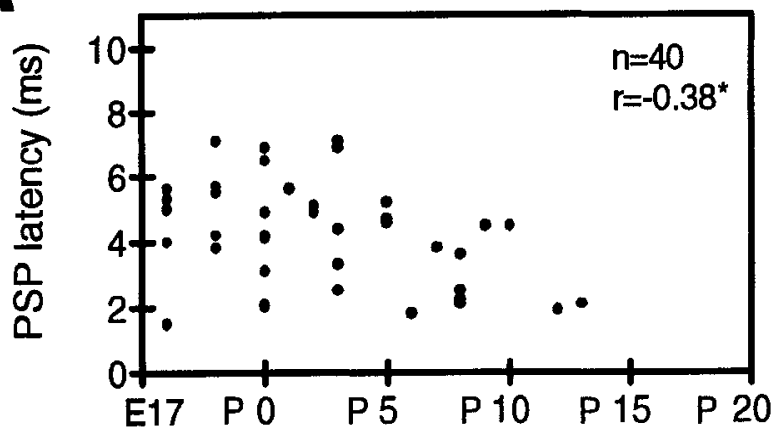

B
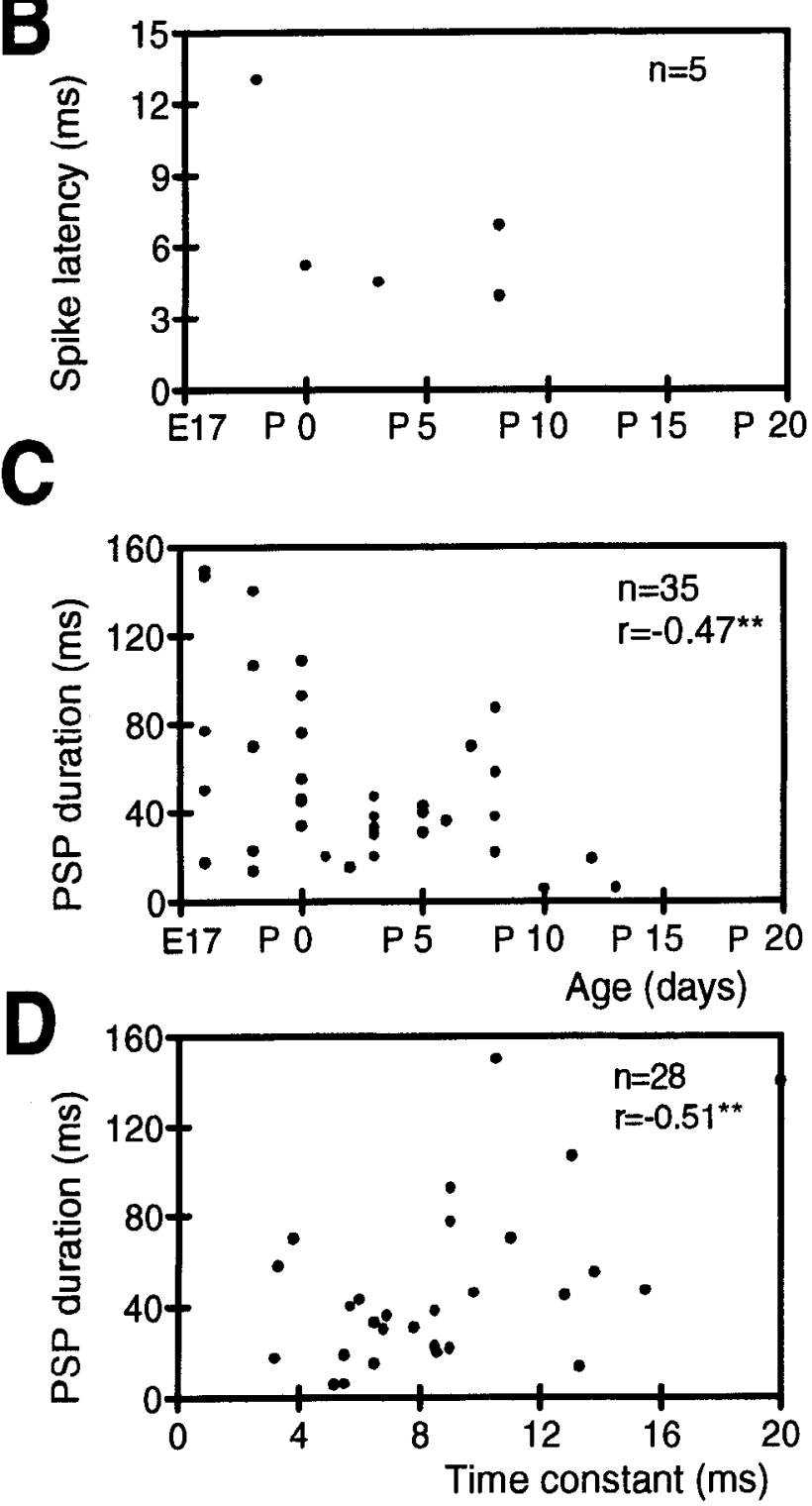

remaining SOC
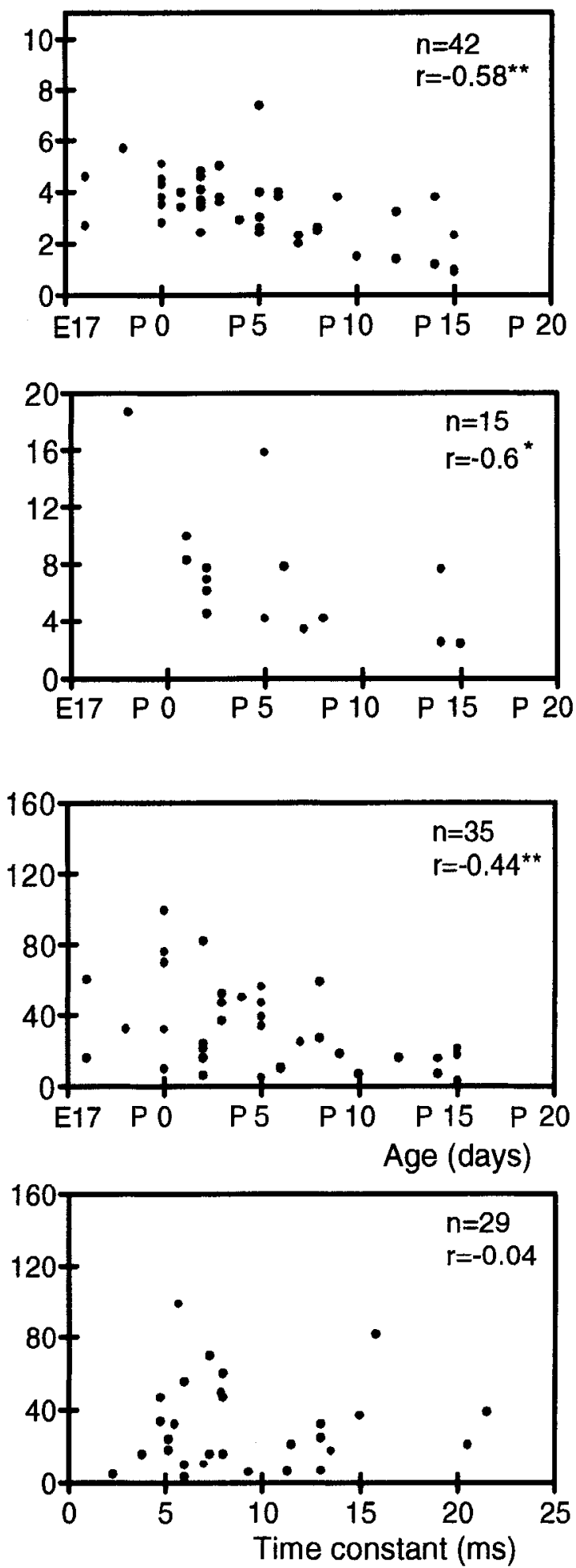

Figure 5. Quantitative analysis of contralaterally elicited PSPs in developing LSO neurons (left column) and in the remaining SOC neurons (right column). A, PSP latencies decrease with increasing age (LSO: $0.01<p<0.05$; SOC: $p<0.001$ ). $B$, In five LSO neurons younger than P8, contralateral stimulation elicited spikes with latencies between $13 \mathrm{msec}$ and $3.9 \mathrm{msec}$. Due to the small sampling size, no correlation analysis was performed. In the remaining SOC neurons, spike latency varied between 18.7 and $2.3 \mathrm{msec}$ and latencies decreased with age $(p<0.05)$. $C$, The half-width duration of contralaterally elicited PSPs declined significantly with age, both in LSO neurons $(p<0.01)$ and in the remaining SOC 
of these neurons remained constant at $-59.0 \pm 6.9 \mathrm{mV}(p>$ $0.1)$ throughout the observation period. The transition from contralaterally elicited depolarizing PSPs to "adult-like," hyperpolarizing PSPs in LSO neurons is therefore not the result of gradually changing $\mathrm{V}_{\text {rest }} \mathrm{s}$, but rather of gradually changing Erevs. In addition to the above-described PSPs, which had negative Erevs, we sometimes $(n=5)$ encountered contralaterally elicited PSPs with positive $\mathrm{E}_{\text {rev }} \mathrm{s}$. In these cases, $\mathrm{E}_{\text {rev }}$ averaged $+21.4 \pm 14.6$ $\mathrm{mV}$. Since this value is very similar to the $\mathrm{E}_{\text {rev }}$ of ipsilaterally elicited PSPs mediated by glutamate $(+19.8 \pm 21.4 \mathrm{mV})$, we concluded that these PSPs represent a weak contralateral glutamatergic input to SOC/LSO neurons. Previous studies in adult mammals have also identificd some excitatory PSPs after contralateral stimulation (Sanes, 1990; Wu and Kelly, 1991). However, due to the very rare occurrence of contralaterally elicited PSPs with positive $\mathrm{E}_{\mathrm{rev}} \mathrm{s}$, we performed no further analysis, such as pharmacological tests.

Pharmacology of contralaterally elicited PSPs in LSO neurons. In order to test whether the contralaterally elicited depolarizing PSPs were caused by glycine (the neurotransmilter of MNTB axons in adult animals; Bledsoe et al., 1990), we applied the specific glycine antagonist strychnine (Young and Snyder, $1973,1974)$ into the bath solution while stimulating the contralateral input. As shown in the examples in Figure 4, strychnine totally and reversibly blocked the contralaterally elicited depolarizing PSPs in perinatal LSO neurons, as well as the hyperpolarizing PSPs in older neurons $(n=8)$. This demonstrates that contralaterally elicited depolarizing PSPs in perinatal LSO neurons are, indeed, caused by glycine, acting on the "inhibitory," strychnine-sensitive glycine receptor. Figure 4 also shows that higher strychnine concentrations were necessary to suppress PSPs in perinatal LSO neurons than in older LSO neurons. This observation is consistent with the fact that an immature, "neonatal" isoform of the glycine receptor, which is known to have lower strychnine sensitivity (Becker et al., 1988), is expressed in developing LSO neurons of the rat (Friauf et al., 1994).

In summary, our results on the contralateral synaptic transmission to SOC neurons demonstrate that stimulation of these afferent fibers results in depolarizing PSPs in perinatal LSO neurons (E18-P4) and in "adult-like," hyperpolarizing PSPs in LSO neurons from older rats ( $>$ P8). Depolarizing as well as hyperpolarizing PSPs were blocked by strychnine, indicating that both types of responses are caused by glycine acting on the "inhibitory," strychnine-sensitive glycine receptor.

\section{Pharmacology of glycine responses in developing SOC neurons}

To further characterize glycine responses in developing SOC neurons, we examined the effects of externally applied drugs. In 33 of 35 neurons ( $94 \%$ ), bath application of glycine (0.1-20 mM, 1-2 min pulses) was followed by an increase of the membrane conductance (range 4-95\%), as would be expected from the opening of glycine-gated ion channels. Consistent with our results obtained after electrical stimulation, bath-applied glycine hyperpolarized LSO neurons from older animals, but depolarized LSO neurons in perinatal rats. Figure 8 illustrates two examples of the effect of glycine in a P12- and a P0-LSO neuron.
In both neurons, the glycine effects were characterized by an increase in the membrane conductance, as evidenced by a decrease in membrane potential deflections due to injections of short $(500 \mathrm{msec})$ current pulses. The conductance increase was accompanied by a hyperpolarization in the P12 neuron (maximum: $-10.5 \mathrm{mV}$ ), but by a depolarization in the P0 neuron (maximum: $+11.5 \mathrm{mV}$ ). Bath application of strychnine reversibly blocked the glycine-induced responses (Fig. 8, middle and lower traces), indicating that externally applied glycine activated strychnine-sensitive glycine receptors. This was further supported by the action of the glycine agonist $\beta$-alanine (Pfeiffer et al., $1982)$, which mimicked both glycinergic depolarization $(n=5$, $\mathrm{P} 0-\mathrm{P} 8)$, as wcll as hypcrpolarization $(n=1, \mathrm{P} 12)$.

Figure 9 summarizes the results of the glycine effects on 20 LSO neurons from E18 to P12. There was no age dependency in the amount of glycine-induced increases of the membrane conductance (Fig. 9A), but there was a gradual transition from depolarizing responses in embryonic and early postnatal animals, to hyperpolarizing responses in animals older than P8 (Fig. $9 B, C$ ). The time course of this transition closely reflects the agedependent changes from contralaterally elicited depolarizing PSPs to "adult-like," hyperpolarizing PSPs (Fig. 9D). This further indicates that the transition from contralaterally elicited depolarizing to hyperpolarizing PSPs in developing LSO neurons is caused by changes in the action of glycine on postsynaptic LSO neurons, rather than by presynaptic mechanisms in afferent MNTB fibers.

The effects of glycine and its antagonization by strychnine were dose dependent (Fig. 10). The average Hill cocfficient for glycine-induced membrane potential changes was $1.9 \pm 0.25$ ( $n$ $=4$, Fig. 11), indicating that two molecules of glycine are necessary to activate a glycine receptor molecule in perinatal LSO neurons. Similar Hill coefficients have been previously reported for the "neonatal" isoform of the strychnine-sensitive glycine receptor (Kuhse et al., 1990; Ito and Cherubini, 1991; FatimaShad and Barry, 1992), which is expressed by LSO neurons in perinatal rats (Friauf et al., 1994).

As the total input to LSO neurons in perinatal rats is not known, one may argue that glycine-induced depolarizations in LSO neurons are caused by disinhibition of a spontaneously active excitatory input to the LSO. In order to exclude such an indirect polysynaptic action, we applied glycine in the presence of the glutamate antagonist kynurenic acid ( $n=3$ neurons; E20P6). As shown in Figure 12A, glycinergic depolarizations were not blocked in the presence of $1 \mathrm{~mm}$ kynurenic acid, indicating the effect of glycine directly on the recorded neurons. This result, together with the fact that NMDA receptor antagonists (10 $\mu \mathrm{M}$ MK801, $n=2 ; 100 \mu \mathrm{M} \mathrm{APV}, n=2$ ) did not influence glycine effects (data not shown), further rules out the possibility that glycine sensitizes extrasynaptic NMDA receptors (Zhou and Parks, 1992), which could then be activated by ambient glutamate in the slice (Lo Turco et al., 1991).

As indicated above, strychnine-sensitive glycine receptors are expressed in two developmentally regulated isoforms. Both the "adult" and the "neonatal" isoform of glycine receptors are ligand-coupled ion channels that are permeable to small monovalent anions (Bormann et al., 1987; Kuhse et al., 1990; Morales 
A

$V_{m}(m V)$

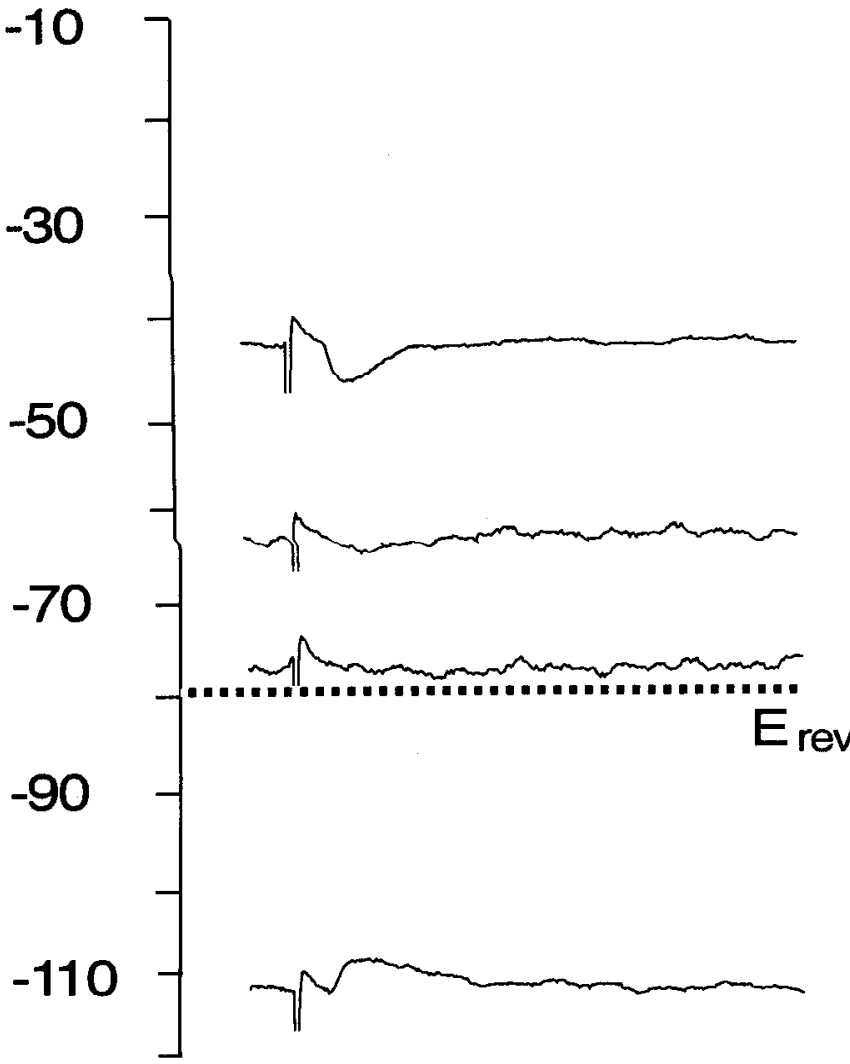

C

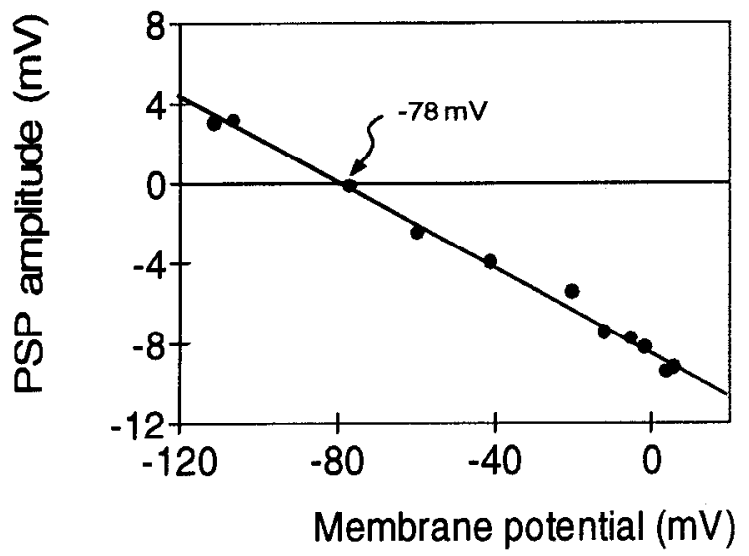

P3
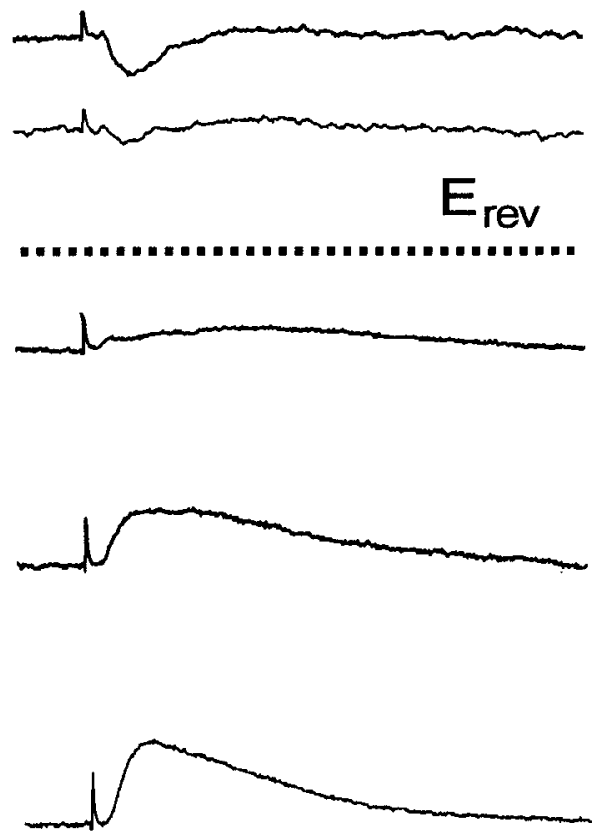

$20 \mathrm{~ms}$

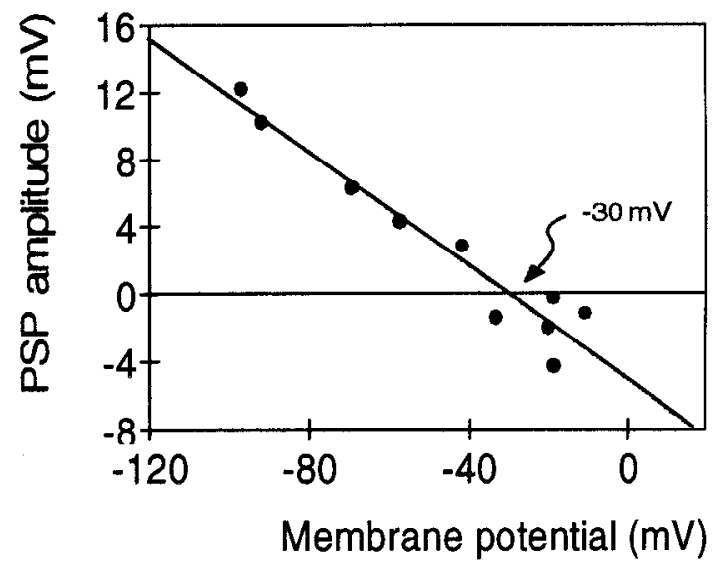

Figure 6. Reversal potentials of contralaterally elicited PSPs. $A$ and $C$, Examples of contralaterally elicited PSPs in two LSO neurons at different membrane potentials. A, P10 neuron. At membrane potentials more positive than the reversal potential of $-78 \mathrm{mV}$ ( $E_{\text {contra }}$ dashed line), contralateral stimulation elicited hyperpolarizing PSPs (upper three traces). At more negative membrane potentials, these PSPs reversed into depolarizing PSPs (lower truce). $\mathrm{V}_{\text {rest }}$ was $-57 \mathrm{mV}$. B. Example of a $\mathrm{P} 3$ neuron with an $\mathrm{L}_{\text {rev }}$ of $-30 \mathrm{mV}$ (dashed line). $\mathrm{V}_{\text {rest }}$ was $65 \mathrm{mV}$. Traces are the avcragc of three to five single sweeps. $C$ and $D$, PSP amplitudes at different membrane potentials. Data are from the same neurons shown in $A$ and $B$. For each neuron, $E_{\text {rev }}$ was determined as the point of intersection between the linear regression line and the $0 \mathrm{mV}$ line. Each dot represents the average amplitude of five PSPs. 


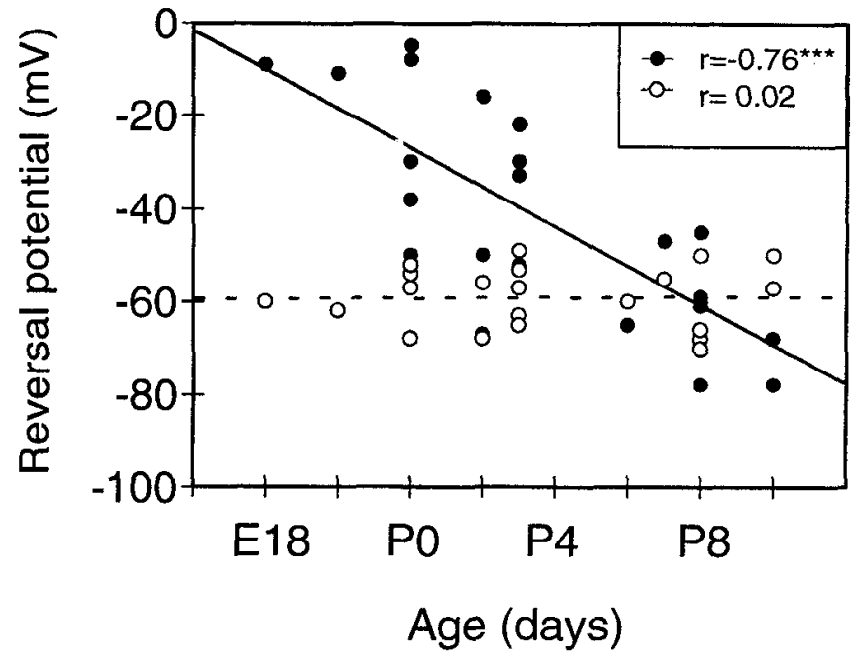

Figure 7. Age dependency of $\mathrm{E}_{\text {rev }} \mathrm{s}$ of contralaterally elicited PSPs and $\mathrm{V}_{\text {rest }}$ in LSO neurons. There was a highly significant decrease in the values of $\mathrm{E}_{\text {rev }} \mathrm{s}$ (closed circles) with increasing age $(r=0.76, p<$ 0.001 ). In contrast, $\mathrm{V}_{\text {rest }}$ (open circles) did not change between E18 and $\mathrm{P} 10(p>0.1)$. The linear regression line for the $\mathrm{E}_{\text {rev }}$ crosses the average $\mathrm{V}_{\text {rest }}$ at P8, which means that contralaterally elicited PSPs are depolarizing before $\mathrm{P} 8$, and hyperpolarizing thereafter. et al., 1994). In adult neurons, opening of these ion channels results in an influx of $\mathrm{Cl}^{-}$ions and, consequently, in the hyperpolarization of the cell membrane. In immature neurons, the observed depolarizing glycine effects could be achieved by an efflux of $\mathrm{Cl}^{-}$ions due to a reversed driving force for $\mathrm{Cl}^{-}$ions. Because the external $\mathrm{Cl}^{-}$concentration was always the same in our experiments $(138 \mathrm{~mm})$ and since $V_{\text {rest }}$ of LSO neurons did not change with age, these two parametcrs cannot be responsible for changes in the driving force for $\mathrm{Cl}^{-}$ions. In order to test whether high intracellular $\mathrm{Cl}^{-}$concentrations underly glycinergic depolarization, we made several attempts to manipulate the $\mathrm{Cl}^{-}$driving force by changing internal and external $\mathrm{Cl}^{-}$concentrations. First, we used electrodes filled with potassium chloride instead of potassium acetate. Second, we replaced extracellular sodium chloride with sodium isothionate and, third, we tried to block cellular chloride pumps with furosemide $(0.5 \mathrm{mM})$. Unfortunately, all of these manipulations resulted in severe instabilities of the recordings, thus making it impossible to interpret the results that we could gather from the few surviving neurons. Therefore, in order to test whether the glycinergic depolarizations observed in perinatal SOC neurons were caused by a transmembrane $\mathrm{Cl}^{-}$efflux, we used an indirect approach; we applied the inhibitory neurotransmitter $\gamma$-aminobutyric acid (GABA). GABAergic synapses on LSO neurons have been previously de-

\section{$\mathrm{P} 12$}

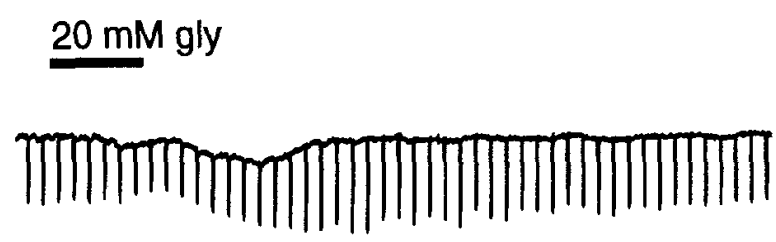

$$
20 \mathrm{mM} \text { gly }
$$

$10 \mu \mathrm{M}$ stry
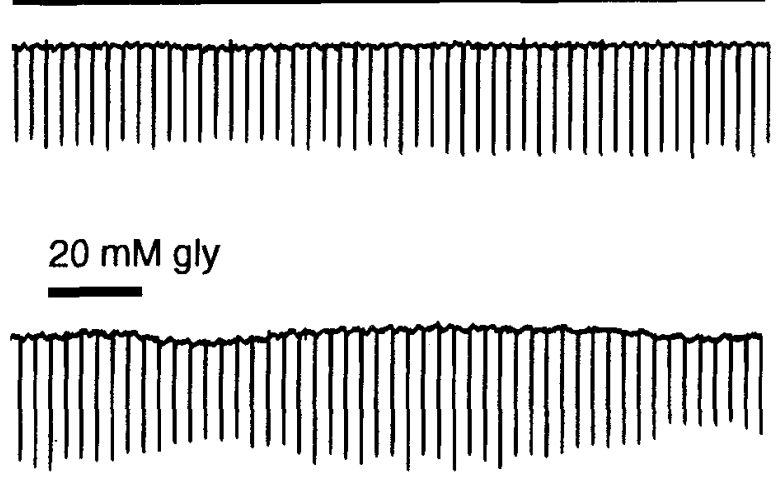

PO
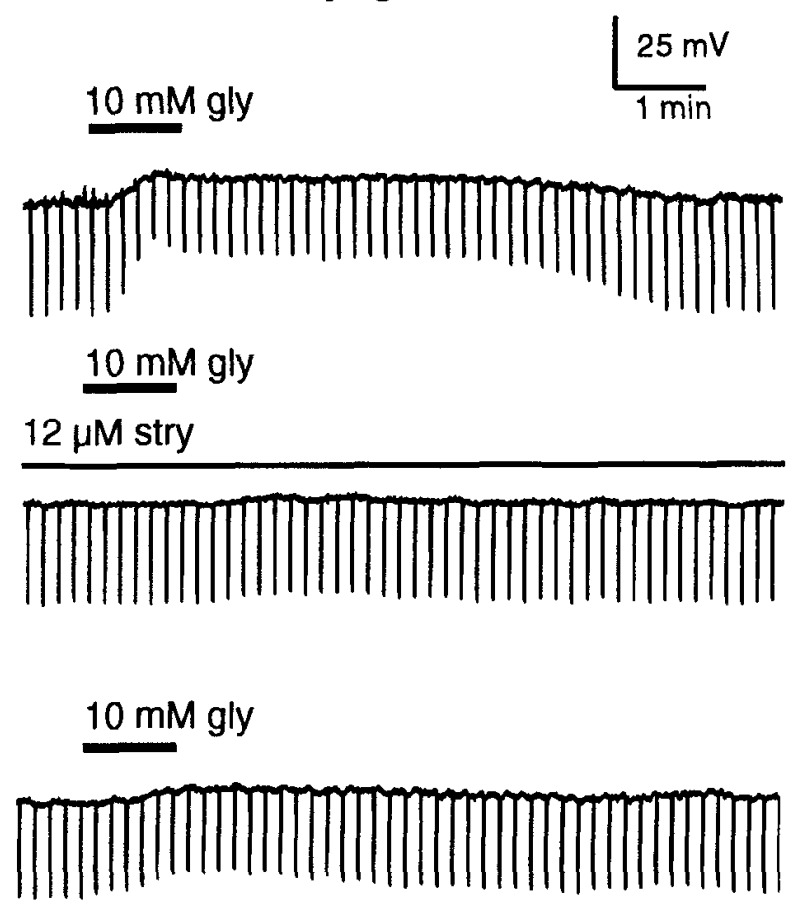

Figure 8. Age-dependent effects of bath-applied glycine on LSO neurons. Left column: P12 neuron. Right column: P0 neuron. The short downward deflections of $\mathrm{V}_{\mathrm{m}}$ are the results of short hyperpolarizing current injections ( $500 \mathrm{msec}, 0.1 \mathrm{~Hz}, 0.25 \mathrm{nA}$ at P12 and $0.28 \mathrm{nA}$ at P0) through the recording electrode in order to determine the input resistance $\left(R_{\mathrm{i}}\right)$. Upper traces, in both neurons, glycine decreased $\mathrm{R}_{\mathrm{i}}$ as indicated by the decrease in the current-induced deflections of $\mathrm{V}_{\mathrm{m}}$. In the P12 neuron, $\mathrm{R}_{\mathrm{i}}$ dropped to $63 \%$, in the P0 neuron $\mathrm{R}_{\mathrm{i}}$ dropped to $56 \%$ of its initial value. In the P12 neuron, application of glycine resulted in a hyperpolarization $(\max .-10.5 \mathrm{mV})$; in the P0 neuron, it resulted in a depolarization (max. $+11.5 \mathrm{mV})$. Middle traces: strychnine blocked both the decrease in $\mathrm{R}_{;}$and changes in $\mathrm{V}_{\mathrm{m}}$. Lower traces: partial recovery of the glycine responses after a 40 min washout of strychnine. At the end of the recording, the P12 neuron became instable and was lost shortly after the recording. $V_{\text {rest }}$ was -65 $\mathrm{mV}$ in the P12 neuron and $-56 \mathrm{mV}$ in the PO neuron. 
A
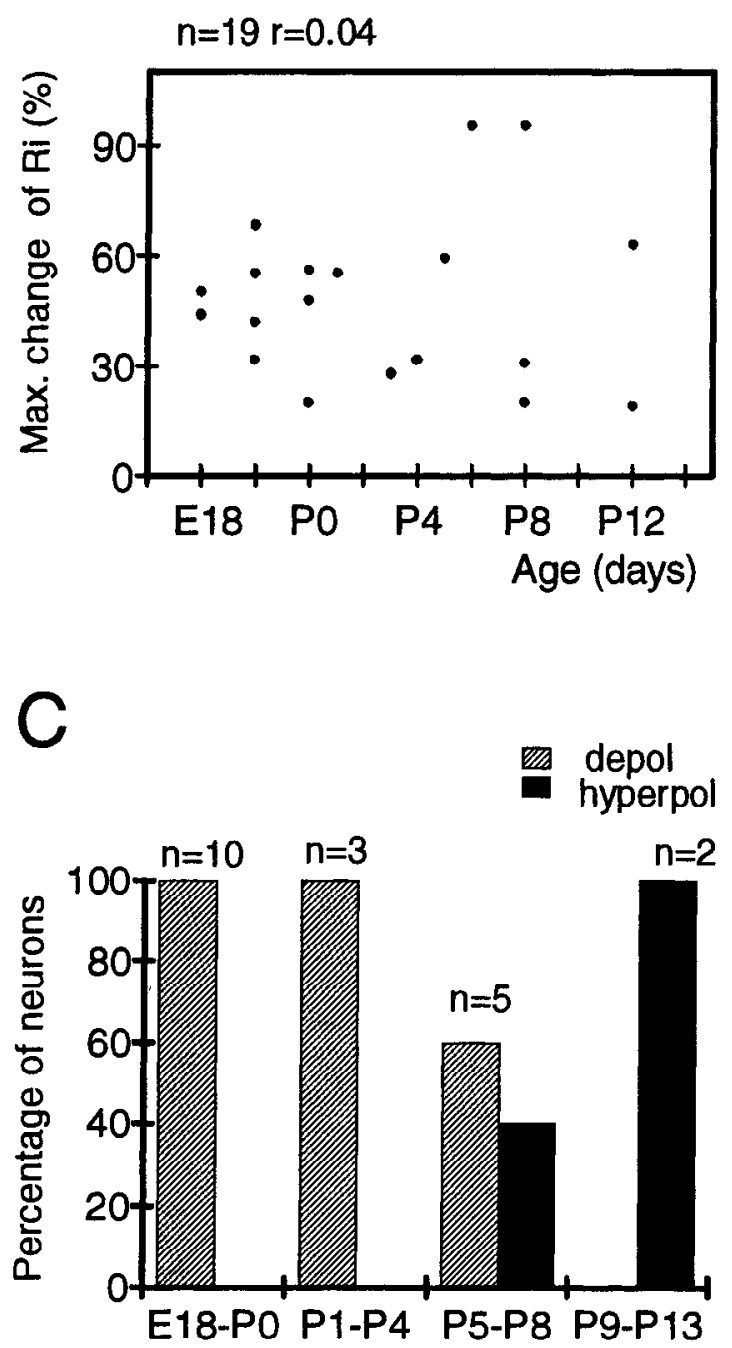

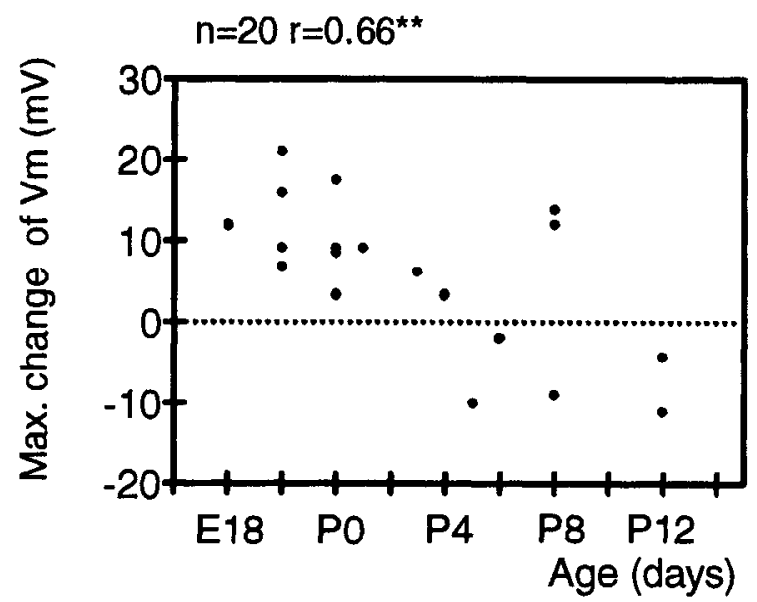

D depol. PSP hyperpol. PSP

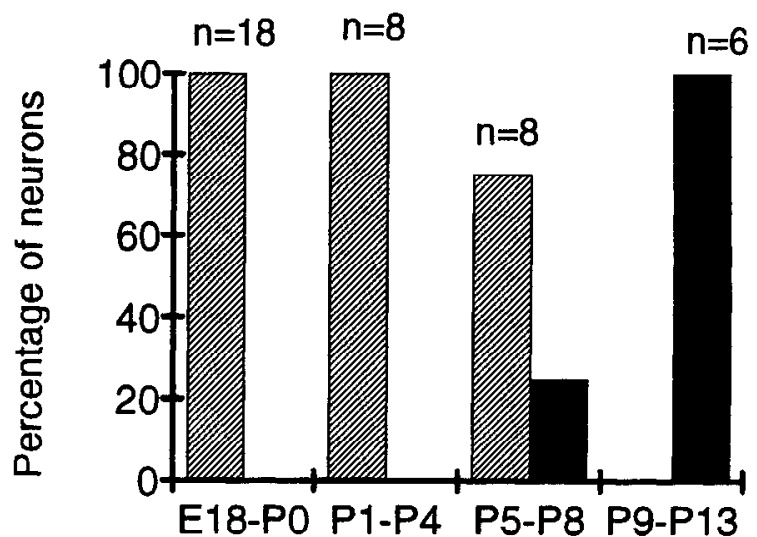

Figure 9. Summary of glycine effects on developing LSO neurons. $A$, Maximum change of $\mathrm{R}_{\mathrm{i}}$ induced by glycine. Changes in $\mathrm{R}_{\mathrm{i}}$ are not a function of age $(p>0.1)$. B. Glycine-induced changes in $V_{m}$. In animals younger than $\mathrm{P} 4$, glycine always depolarized the neurons. Between $\mathrm{P} 5$ and P8, the effects of glycine were variable in that some LSO neurons were depolarized and others hyperpolarized. At P12, glycine only hyperpolarized neurons. Changes in $\mathrm{V}_{\mathrm{m}}$ were age dependent $(p<0.01) . C$ and $D$, Frequency distribution of observed depolarizations (striped) and hyperpolarizations (solid black) caused by bath application of glycine $(C)$ or by electrical stimulation of the contralateral input $(D)$. Notice that in both cases, the transition from depolarizing to hyperpolarizing responses occurred between P5 and P8.

scribed (Helfert et al., 1992; Roberts, 1993). Bath application of GABA (0.1-5 mM), which increases chloride conductances by activating $\mathrm{GABA}_{\mathrm{A}}$ receptors (Bormann, 1988), reduced the membrane resistance and changed the membrane potential in 10 out of 13 neurons that had been initially shown to be glycinesensitive (Fig. 12C). Furthermore, all GABA-induced membrane potential changes had the same polarity as those caused by glycine (Fig. 12B,C). GABA effects could not be antagonized with strychnine, enabling us to exclude the possibility that GABA activated glycine receptors. Although these results do not directly prove the mechanisms underlying glycine-induced depolarizations in perinatal LSO neurons, they strongly suggest that the glycinergic depolarizations are caused by $\mathrm{Cl}^{-}$efflux due to a high intracellular $\mathrm{Cl}^{-}$concentration, similar to the situation seen in embryonic spinal cord neurons (Wu et al., 1992; Reichling et al., 1994; Wang et al., 1994).

In summary, externally applied glycine, via activation of "in- hibitory," strychnine-sensitive glycine receptors, depolarizes SOC neurons during the same period at which contralaterally elicited glycinergic PSPs are depolarizing. Although there is no direct evidence, our pharmacological experiments suggest that the depolarizing action of glycine is the result of a high intracellular $\mathrm{Cl}^{-}$ concentration in perinatal SOC neurons, causing an efflux of $\mathrm{Cl}^{-}$ ions through the glycine-gated ion channels.

\section{Discussion}

The present study has used intracellular recordings made from brainstem slices to describe the development of synaptic transmission to identified SOC neurons in perinatal rats. SOC neurons generate PSPs in response to electrical stimulation of the ipsilateral and contralateral input fibers as early as E18, i.e., around the time when cochlear nucleus axons in the VAS send axon collaterals into the SOC (Kandler and Friauf, 1993a). During the following 3 weeks, PSP latencies decrease and PSP durations 

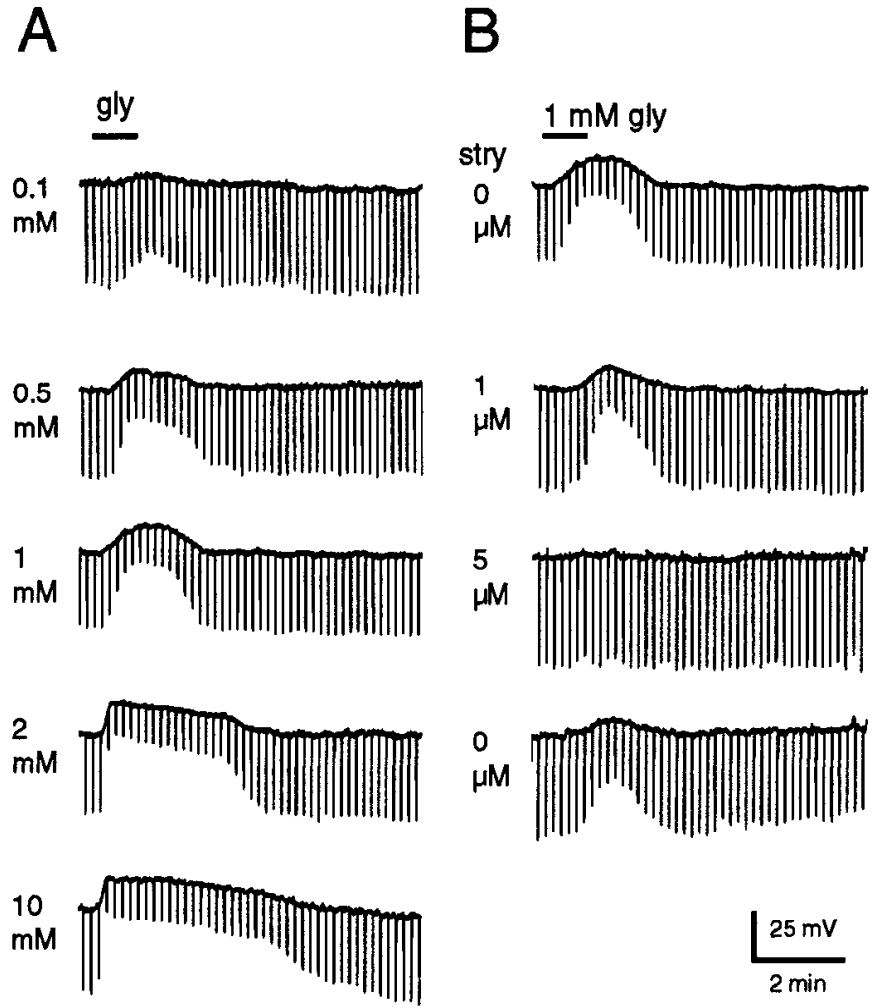

Figure 10. Dose dependency of the effects of glycine and strychnine. $A$, Application of glycine $(g l y)$ in concentrations from 0.1 to $10 \mathrm{mM}$. Increasing concentration resulted in a stronger reduction of $R_{i}$, a higher depolarization of $\mathrm{V}_{\mathrm{m}}$, and a longer response duration. $B$, Strychnine antagonized the effects of glycine in a dose-dependent manner (stry). Strychnine $(1 \mu \mathrm{M})$ partly blocked the effect of $1 \mathrm{mM}$ glycine, and $5 \mu \mathrm{M}$ strychnine blocked it completely. Glycine effects were partly restored after a $50 \mathrm{~min}$ washout of strychnine $\left(0 \mu \mathrm{M}\right.$ stry). $\mathrm{V}_{\text {rest }}$ was $-57 \mathrm{mV}$.

shorten. Most interestingly, contralateral stimulation elicits depolarizing PSPs in embryonic and early postnatal LSO neurons and "adult-like," hyperpolarizing PSPs in LSO neurons from animals older than 1 week; regardless of sign, these contralaterally elicited PSPs are mediated by glycine, acting on strychninesensitive glycine receptors.

\section{Developmental changes in latency and duration of synaptic responses}

We found a reduction in both the latency and the duration of ipsilaterally and contralaterally elicited PSPs between E18 and P17. This aspect of PSP maturation in SOC neurons is consistent with what is known about the development of the auditory system (Wu and Oertel, 1987; Sanes, 1993) as well as in other brain structures (Schwartzkroin and Kunkel, 1982; Kriegstein et al., 1987; Hestrin, 1992; Purpura et al., 1994). In LSO neurons, some of the PSP shortening can be explained by a decrease of the membrane time constant (Kandler and Friauf, 1995). Additional factors that are likely to contribute to PSP shortening are a decrease in the number of axons converging on single neurons (Sanes and Siverls, 1991; Sanes, 1993) or a decrease in the open time of glycine receptor-activated channels (Takahashi et al., 1992; Morales et al., 1994). This latter factor appears to be of particular relevance during the first 2 postnatal weeks when LSO neurons switch from the "neonatal" to the "adult" isoform of the glycine receptor (Friauf et al., 1994), which have long and short open times, respectively (Takahashi et al., 1992).

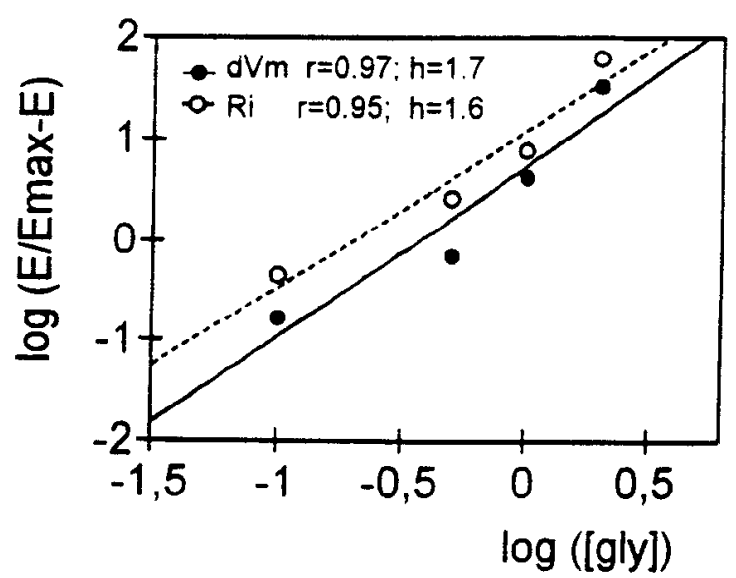

Figure 11. Hill diagram of glycine-induced depolarizations in an E20 neuron. The linear regression line for changes in $\mathrm{R}_{\mathrm{i}}$ (open circles, broken line) has a slope $(h)$ of 1.6 (Hill coefficient), the one for depolarization (filled circles, solid line) has a slope of 1.7 . These values indicate that two molecules of glycine are necessary to activate the strychnine-sensitive glycine receptor.

\section{Development of ipsilateral synaptic transmission}

Electrical stimulation of the ipsilateral VAS elicited depolarizing, subthreshold PSPs at E18 and suprathreshold PSPs from E20 on. Antidromic action potentials were also recorded at E20, and it is known that SOC neurons already project to the inferior colliculus at that time (Friauf and Kandler, 1990; unpublished observations). Therefore, rat auditory brainstem neurons are capable of relaying neuronal activity from the cochlear nucleus to the inferior colliculus about $2 \mathrm{~d}$ before birth and more than 2 weeks before the onset of hearing (Uziel et al., 1981).

The glutamate antagonist CNQX completely blocked ipsilaterally elicited PSPs. Therefore, glutamate, acting on postsynaptic non-NMDA receptors, appears to be the excitatory transmitter in the developing projection from the cochlear nucleus to the LSO. However, since we only tested CNQX under our standard protocol ( $\mathrm{V}_{\mathrm{m}}$ at rest, $2.4 \mathrm{mM} \mathrm{Mg}^{2+}$ in the bath solution), we cannot exclude the possibility that NMDA receptors might be activated under more special conditions, for example following high frequency stimulation.

\section{Development of contralateral synaptic transmission}

Electrical stimulation of the contralateral afferent fibers elicited PSPs in SOC neurons even in the youngest animals studied (i.e., E18). These PSPs were depolarizing until about the end of the first postnatal week, when hyperpolarizing PSPs, similar to those in the the adult (Finlayson and Caspary, 1989; Sanes, 1990; Wu and Kelly, 1992), were observed in LSO neurons. Since both depolarizing and hyperpolarizing PSPs could be completely and reversibly blocked by strychnine, it is clear that both types of PSP are caused by glycine receptors, most likely activated by presynaptic MNTB axons, the main source of contralateral input to the LSO (review, Schwartz, 1992). The depolarizing action of glycine was further confirmed by the fact that the changes in glycine-induced or $\beta$-alanine-induced membrane potentials follow the same gradual, age-dependent transition from depolarization to hyperpolarization as the contralaterally elicited PSPs do. We are therefore convinced that the observed switch in the polarity of contralaterally elicited PSPs is caused by mechanisms in the postsynaptic LSO neurons, most likely by a decrease in the intracellular $\mathrm{Cl}^{-}$concentration. Our results are in line with 


\section{A}

$1 \mathrm{mM}$ gly

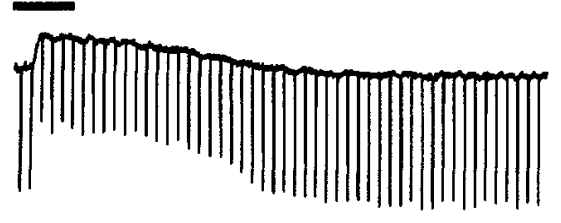

$1 \mathrm{mM}$ gly

$1 \mathrm{mM} \mathrm{kyn}$

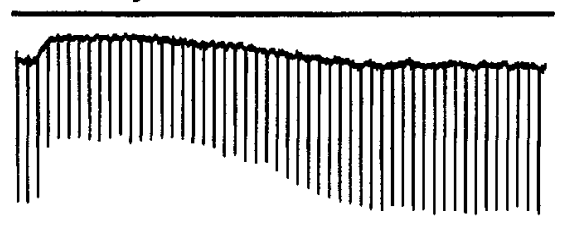

B
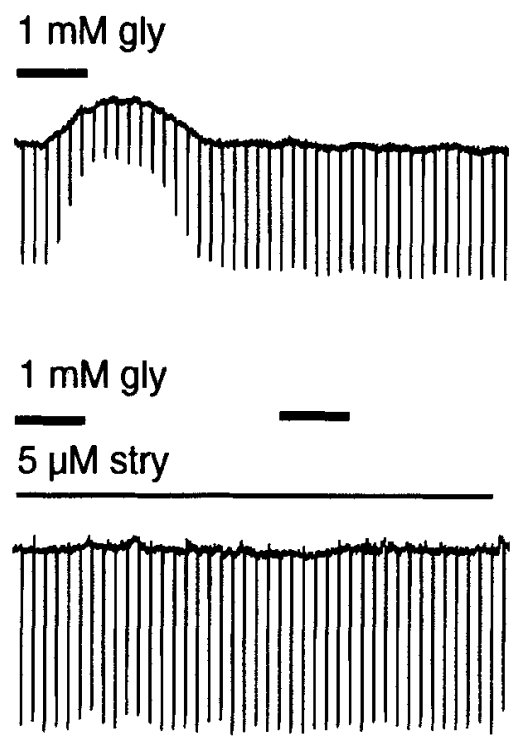

2 mM GABA

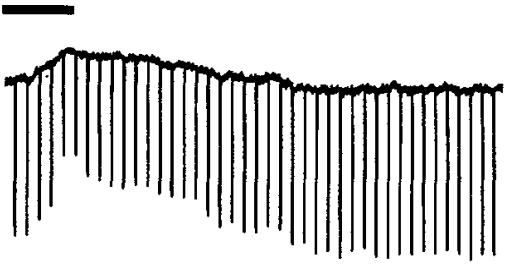

2 mM GABA

$5 \mu \mathrm{M}$ stry

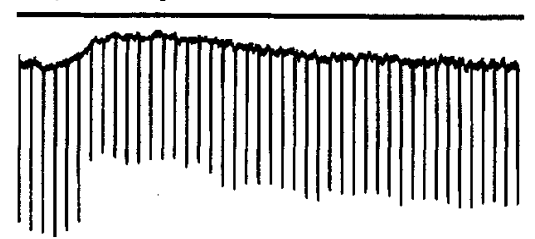

Figure 12. A,Glycinergic depolarizations were not blocked by glutamate antagonists. Upper trace shows the control response to 1 mm glycine $($ gly $)$. In the lower trace, $1 \mathrm{~mm}$ glycine was applied in the presence of $1 \mathrm{~mm}$ kynurenic acid $(k y n)$. During the recording, $\mathrm{V}_{\text {rest }}$ slightly depolarized from $-65 \mathrm{mV}$ to $-61 \mathrm{mV}$, which resulted in a slightly lower amplitude of the glycine-induced depolarization. $B$, For a comparison with $C$, the strychnine-sensitive glycine effects on a E20-SOC neuron are shown. $C$, Bath application of $2 \mathrm{~mm}$ GABA causes a decrcasc in $\mathrm{R}_{\mathrm{i}}$ and depolarization of $\mathrm{V}_{\mathrm{m}}$. Strychnine $(5 \mu \mathrm{M})$ did not block these GABA responses. $\mathrm{V}_{\text {rest }}$ was $-59 \mathrm{mV}$.

several other studies that demonstrated depolarizing effects of glycine or GABA during development (Cherubini et al., 1991; Ito and Cherubini, 1991; Wu et al., 1992; Reichling et al., 1994). Our results, however, contrast with a study in the LSO of the
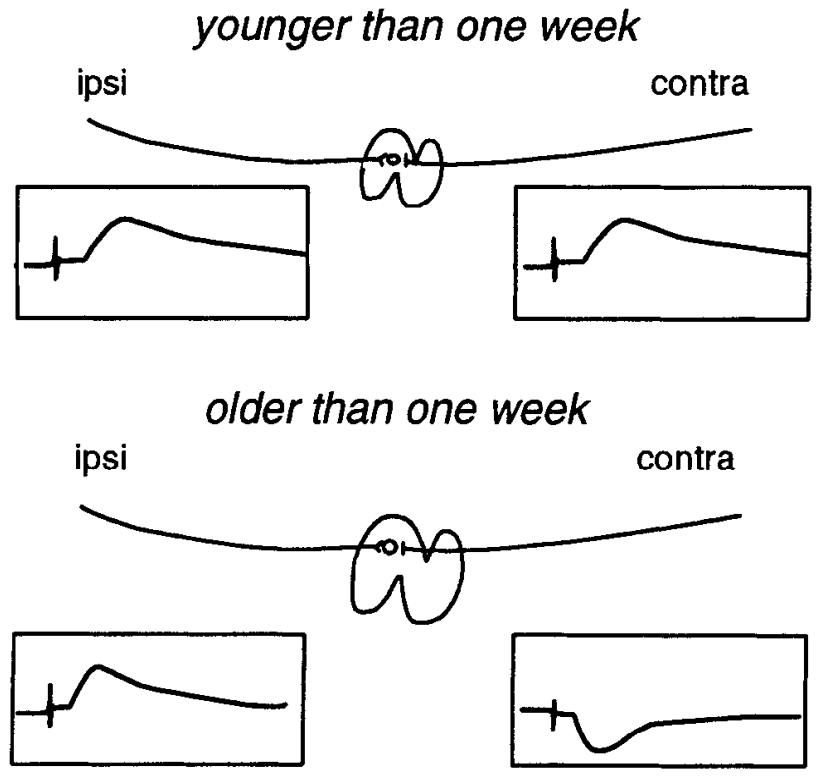

Figure 13. Schematic drawing of the development of the ipsilateral and contralateral synaptic transmission to the LSO. In animals younger than 1 week, both the ipsilateral, glutamatergic (ipsi), as well the contralateral, glycinergic input (contra) are excitatory. PSP latencies and PSP durations are long. In animals older than 1 week, the adult situation is achieved in which the ipsilateral input is excitatory and the contralateral input is inhibitory, enabling the LSO to code interaural intensity differences. neonatal gerbil, where hyperpolarizing PSPs were reported to appear between P2-P6 (Sanes, 1993). Because the latter study did not identify the neurons morphologically and did not report $V_{\text {rest }}$ for individual neurons, it remains unclear whether different subpopulations of neurons were characterized or whether different values of $\mathrm{V}_{\text {rest }}$ account for the contrasting results. However, a few contralaterally elicited depolarizing PSPs were observed in neonatal gerbils, but they were not further analyzed, because they were regarded as artifactual (Sanes, 1993). Finally, species differences could also be responsible for the contradictory results. A recent anatomical study reported that the connections from the cochlear nuclei to the SOC in the gerbil reach maturity several days earlier than in the rat (Russell and Moore, 1995), raising the possibility that connections of the MNTB in the gerbil also mature earlier and that the switch in the polarity of contralaterally elicited PSPs might occur before P2 in gerbils.

\section{A possible functional role for depolarizing glycinergic PSPs in} LSO neurons

Recent anatomical studies in gerbils have demonstrated that glycinergic MNTB axons, synapsing on LSO neurons, are refined by activity-dependent mechanisms. Axonal arbors of single MNTB axons and dendritic trees of LSO neurons are pruned postnatally by mechanisms, which depend on synaptic activity and on the activation of glycine receptors (Sanes and Chokshi, 1992; Sanes et al., 1992; Sanes and Takacs, 1993). These refinements result in a sharpening of the inhibitory MNTB-LSO projection, similar to the well-known refinement of excitatory connections, for example, in the mammalian visual system (review, Goodman and Shatz, 1993; Cramer and Sur, 1995). The present study demonstrates depolarizing actions of glycine during the developmental stage at which glycine receptor activation is necessary for the refinement of inhibitory afferents to the 
LSO. Early postnatal LSO neurons express voltage-sensitive $\mathrm{Ca}^{2+}$ channels (Schmanns and Friauf, 1994), and under stimulus conditions that have yet to be determined, glycine-induced depolarizations could activate these channels, thereby increasing cytosolic $\mathrm{Ca}^{2+}$ concentrations $\left[\mathrm{Ca}^{2+}\right]_{i}$ in LSO neurons. This scenario would be similar to that which occurs in cmbryonic spinal cord neurons (Reichling et al., 1994; Wang et al., 1994) or in neonatal neocortical neurons (Yuste and Katz, 1991; Lin et al., 1994). The glycinergic MNTB-LSO pathway might therefore transiently behave like an excitatory pathway and use the same $\mathrm{Ca}^{2+}$-dependent cellular mechanisms known to be involved in strengthening and reshaping excitatory connections (Malenka, 1994). This hypothesis gains additional support from the fact that LSO neurons transiently express the calcium-binding protein calbindin- $D_{28 K}$, whose immunoreactivity is high during the same period at which glycine is excitatory (Friauf, 1993), suggesting that regulation of $\left[\mathrm{Ca}^{2+}\right]_{i}$ is especially important during this period. Additionally, early postnatal LSO neurons transiently express the $\mathrm{Ca}^{2+}$-dependent protein kinase $\mathrm{C} \beta \mathrm{II}$ during the same period in which glycine is depolarizing (Garcia and Harlan, 1994). Protein kinase $C$ activation potentiates glycine responses in neurons ( $\mathrm{Gu}$ and Huang, 1994). Nlthough the currently available results support our hypothesis, they are still circumstantial and further experiments are necessary for direct proof.

\section{Developmental state of synaptic transmission in the SOC at the time of hearing onset}

As already mentioned, physiological hearing in rats begins between P12 and P14 (e.g., Uziel et al., 1981). By that age, SOC neurons have already reached a considerable stage of maturity without ever being driven by external, i.e., acoustic stimuli. For example, by P12-P14 ipsilateral PSPs are excitatory and contralateral PSPs are inhibitory in LSO neurons, and both inputs arrive at about the same time as in the adult (Caird and Klinke, 1983; Sanes, 1990). Simulataneous arrival of inhibitory and excitatory input from the two ears is an important prerequisite for comparing interaural intensity differences, a major function of the adult LSO (Caird and Klinke, 1983). Coinciding ipsilateral and contralateral PSPs in LSO neurons at around hearing onset were also reported in brain slices from gerbils (Sanes, 1993). This indicates that the long latencies of sound-evoked LSO responses at the time of hearing onset (Sanes and Rubel, 1988) are probably caused by long latencies in structures peripheral to the SOC. Other mature physiological properties of SOC neurons at the time of hearing onset, including $\mathrm{V}_{\text {ress }}$, spike duration, spike amplitude, and spiking patterns (Kandler and Friauf, 1995), indicate that a great deal of physiological development of SOC neurons occurs without external sensory input. On the other hand, SOC neurons in rats (present study) and LSO neurons in gerbils (Sanes, 1993) display several immature properties at hearing onset. For example, PSPs in SOC neurons around P12 last longer than in adult animals, resulting in strong temporal overlap of inputs and in poor temporal resolution, as was explicitly shown in postnatal LSO neurons in gerbils (Sanes, 1993). In summary, by the time of hearing onset, the SOC of rodents has reached a stage of relative physiological maturity that allows it to perform its basic physiological functions. Since the processes required to achieve this stage occur before external acoustic input can drive the auditory system, we can conclude that the auditory brainstem becomes organized in the absence of sensory experience.

\section{References}

Banks MI, Smith PH (1992) Intracellular recordings from neurobiotinlabeled cells in brain slices of the rat medial nucleus of the trapezoid body. J Neurosci 12:2819-2837.

Becker C-M, Hoch W, Betz H (1988) Glycine receptor heterogeneity in rat spinal cord during postnatal development. EMBO J 7:37173726.

Bledsoe SCJ, Snead CR, Helfert RH, Prasad V, Wenthold RJ, Altschuler RA (1990) Immunocytochemical and lesion studies support the hypothesis that the projection from the medial nucleus of the trapezoid body to the lateral superior olive is glycinergic. Brain Res 517:189194.

Bormann J (1988) Electrophysiology of $\mathrm{GABA}_{\mathrm{A}}$ and $\mathrm{GABA}_{\mathrm{B}}$ receptor subtypes. Trends Neurosci 11:112-116.

Bormann J, Hamill OP, Sakmann B (1987) Mechanism of anion permeation through channels gated by glycine and gamma-aminobutyric acid in mouse cultured spinal neurones. J Physiol (Lond) 385:243286.

Caird D, Klinke R (1983) Processing of binaural stimuli by cat superior olivary complex neurons. Exp Brain Res 52:385-399.

Caspary DM, Faingold CL (1989) Non- $N$-methyl-D-aspartate receptors may mediate ipsilateral excitation at lateral superior olivary synapses. Brain Res 503:83-90.

Caspary DM, Finlayson PG (1991) Superior olivary complex: functional neuropharmacology of the principal cell types. In: Neurobiology of hearing: the central auditory system (Altschuler RA, Bobbin RP, Clopton BM, Hoffman DW, eds), pp 141-161. New York: Raven.

Cherubini E, Gaiarsa JL, Ben-Ari Y (1991) GABA: an excitatory transmitter in early postnatal life. Trends Neurosci 14:515-519.

Cramer and Sur (1995) Activity-dependent remodeling of connections in the mammalian visual system. Curr. Opin. Neurobiol. 5:106-111.

Fatima-Shad K, Barry P (1992) A patch-clamp study of GABA- and strychnine-sensitive glycine-activated currents in postnatal tissue-cultured hippocampal neurons. Proc R Soc Lond [Biol] 250:99-105.

Finlayson PG, Caspary DM (1989) Synaptic potentials of chinchilla lateral superior olivary neurons. Hear Res 38:221-228.

Forsythe ID, Barnes-Davies M (1993) The binaural auditory pathway: excitatory amino acid receptors mediate dual timecourse excitatory postsynaptic currents in the rat medial nucleus of the trapezoid body. Proc R Soc Lond [Biol] 251:151-157.

Friauf E (1993) Transient appearance of calbindin- $D_{28 k}$-positive neurons in the superior olivary complex of developing rats. J Comp Neurol 334:59-74.

Friauf E, Kandler K (1990) Auditory projections to the inferior colliculus of the rat are present by birth. Neurosci Lett 120:58-61.

Friauf E, Hammerschmidt B, Kirsch J, Betz H (1994) Development of glycine receptor distribution in the rat auditory brainstem: transition from the 'neonatal' to the 'adult' isoform. Assuc Res Otolaryngol Abstr 17:10.

Garcia MM, Harlan RE (1994) Postnatal development of three isoforms of protein kinase $\mathrm{C}$ in central auditory pathways of the rat brain. Soc Neurosci Abstr 20:1106.

Goodman CS, Shatz CJ (1993) Developmental mechanisms that generate precise patterns of neuronal connectivity. Neuron 10:77-98.

Gu Y, Huang L-YM (1994) Modulation of glycine receptor mediated chloride responses by protein kinase C. Soc Neurosci Abstr 20:933.

Helfert RH, Juiz JM, Bledsoe SC, Bonneau JM, Wenthold RJ, Altschuler RA (1992) Patterns of glutamate, glycine, and GABA immunolabeling in four synaptic terminal classes in the lateral superior olive of the guinea pig. J Comp Neurol 323:305-325.

Hestrin S (1992) Developmental regulation of NMDA receptor-mediated synaptic currents at a central synapse. Nature 357:686-689.

Horikawa K, Armstrong WE (1988) A versatile means of intracellular labeling: injection of biocytin and its detection with avidin conjugates. J Neurosci Methods 25:1-11.

Irvine DRF (1992) Physiology of the auditory brainstem. In: The mammalian auditory pathway: neurophysiology (Popper AN, Fay RR, eds), pp 153-231. New York: Springer.

Ito S, Cherubini E (1991) Strychnine-sensitive glycine responses of neonatal rat hippocampal neurones. J Physiol (Lond) 440:67-83.

Kandler K, Friauf E (1992) Early onset of synaptic transmission to neurons in the superior olivary complex of the rat. Soc Neurosci Abstr 18:383.

Kandler K, Friauf E (1993a) Pre- and postnatal development of efferent 
connections of the cochlear nucleus in the rat. J Comp Neurol 328: 161-184.

Kandler K, Friauf E (1993b) Pharmacology of early synaptic transmission in the superior olivary complex of the rat. Soc Neurosci Abstr 19:889.

Kandler K, Friauf E (1995) Development of electrical membrane properties and discharge characteristics of superior olivary complex neurons in fetal and postnatal rats. Eur $\mathbf{J}$ Neurosci, in press.

Kita H, Armstrong WE (1991) A biotin-containing compound N-(2aminoethyl) biotinamide for intracellular labeling and neuronal tracing studies: comparison with biocytin. J Neurosci Methods 37:141150.

Kriegstein AR, Suppes T, Prince DA (1987) Cellular and synaptic physiology and epileptogenesis of developing rat neocortical neurons in vitro. Dev Brain Res 34:161-171.

Kuhse J, Schmieden V, Betz H (1990) A single amino acid exchange alters the pharmacology of neonatal rat glycine receptor subunit. Neuron 5:867-873.

Lin MH, Takahashi MP, Takahashi Y, Tsumoto T (1994) Intracellular calcium increase induced by GABA in visual cortex of fetal and neonatal rats and its disappearance with development. Neurosci Res 20:85-94.

Lo Turco JJ, Blanton MG, Kriegstein AR (1991) Initial expression and endogenous activation of NMDA channels in early ncocortical development. J Neurosci 11:792-799.

Malenka RC (1994) Synaptic plasticity in the hippocampus: LTP and LTD. Cell 78:535-538.

McCormick DA, Prince DA (1987) Post-natal development of electrophysiological properties of rat cerebral cortical pyramidal neurones. J Physiol (Lond) 393:743-762.

Moore DR (1992) Trophic influences of excitatory and inhibitory synapses on neurones in the auditory brain stem. Neuroreport 3:269272.

Morales A, Nguyen QT, Miledi R (1994) Electrophysiological properties of newborn and adult rat spinal cord glycine receptors ex pressed in Xenopus oocytes. Proc Natl Acad Sci USA 91:3097-3101.

Petralia RS, Yokotani N, Wenthold RJ (1994) Light and electron microscope distribution of the NMDA receptor subunit NMDAR1 in the rat nervous system using a selective anti-peptide antibody. J Neurosci 14:667-696.

Pfeiffer F, Graham D, Betz H (1982) Purification by affinity chromatography of the glycine receptor of rat spinal cord. J Biol Chem 257: 9389-9393.

Purpura PR, Shofer RJ, Scarff T (1994) Properties of synaptic activites and spike potentials of neurons in the immature neocortex. J Neurophysiol 28:925-947.

Reichling DB, Kyrozis A, Wang J, Mac Dermott AB (1994) Mechanisms of GABA and glycine depolarization-induced calcium transients in rat dorsal horn neurons. J Physiol (Lond) 476:411-421.

Rietzel H-J, Friauf E (1995) Development of dendritic morphology in the rat auditory brainstem: bipolar and multipolar cells in the lateral superior olive. In: Proceedings of the Göttingen neurobiology conference (Elsner N, Menzel R, eds), p 781. Stuttgart: Thieme.

Roherts WM (1993) Spatial calcium buffering in saccular hair cells Nature 363:74-76.

Russell FA, Moore DR (1995) Afferent reorganisation within the superior olivary complex of the gerbil: devclopment and induction by neonatal, unilateral cochlear removal. J Comp Neurol, in press.

Sanes DH (1990) An in vitro analysis of sound localization mechanisms in the gerbil lateral superior olive. J Neurosci 10:3494-3506.
Sanes DH (1993) The development of synaptic function and integration in the central auditory system. J Neurosci 13:2627-2637.

Sanes DH, Chokshi P (1992) Glycinergic transmission influences the development of dendrite shape. Neuroreport 3:323-326.

Sanes DH, Rubel EW (1988) The ontogeny of inhibition and excitation in the gerbil lateral superior olive. J Neurosci 8:682-700.

Sanes DH, Siverls V (1991) Development and specificity of inhibitory terminal arborizations in the central nervous system. J Neurobiol $8: 837-854$.

Sanes DH, Takacs C (1993) Activity-dependent refinement of inhibitory connections. Eur J Neurosci 5:570-574.

Sanes DH, Markowitz S, Bernstein J, Wardlow J (1992) The influence of inhibitory afferents on the development of postsynaptic dendritic arbors. J Comp Neurol 321:637-644.

Schmanns H, Friauf E (1994) $\mathrm{K}^{+}$- and transmitter-induced rises in $\left[\mathrm{Ca}^{2+}\right]_{i}$ in auditory neurones of developing rats. Ncuroreport 5:23212324.

Schwartz IR (1992) The superior olivary complex and lateral lemniscal nuclei. In: The Inammalian auditory pathway: neuroanatomy (Webster DB, Popper AN, Fay RR, eds), pp 117-167. New York: Springer.

Schwartzkroin PA, Kunkel DD (1982) Electrophysiology and morphology of the developing hippocampus of fetal rabbits. J Neurosci 2:448-462.

Spitzer N (1981) Development of membrane properties in vertebrates. Trends Neurosci 4:169-172.

Takahashi T, Momiyama A, Hirai K, Hishinuma F, Akagi H (1992) Functional correlation of fetal and adult forms of glycine receptors with developmental changes in inhibitory synaptic receptor channels. Neuron 9:1155-1161.

Uziel A, Romand R, Marot M (1981) Development of cochlear potentials in rats. Audiology 20:89-100.

Wang J, Reichling DB, Kyrozis A, Mac Dermott AB (1994) Developmental loss of GABA- and glycinc-induccd depolarization and $\mathrm{Ca}^{2+}$ transients in embryonic rat dorsal horn neurons in culture. Eur J Neurosci 6:1275-1280.

Wu SH, Kelly JB (1991) Physiological properties of neurons in the mouse superior olive: membrane characteristics and postsynaptic responses studied in vitro. J Neurophysiol 65:230-246.

Wu SH, Kelly JB (1992) Synaptic pharmacology of the superior olivary complex studied in mouse brain slice. J Neurosci 12:3084-3097.

Wu SH, Oertel D (1984) Intracellular injection with horseradish peroxidase of physiologically characterized stellate and bushy cells in slices of mouse anteroventral cochlear nucleus. J Neurosci 4:15771588 .

Wu SH, Oertel D (1987) Maturation of synapses and electrical properties of cells in the cochlear nuclei. Hear Res 30:99-110.

Wu WI, Ziskind-Conhaim L, Sweet MA (1992) Early development of glycine- and GABA-mediated synapses in rat spinal cord. J Neurosci 12:3935-3945.

Young AB, Snyder SH (1973) Strychnine binding associated with glycine receptors of the central nervous system. Proc Natl Acad Sci USA 70:2832-2836

Young AB, Snyder SH (1974) Strychnine binding in rat spinal cord membranes associated with the synaptic glycine receptor: cooperativity of glycine interactions. Mol Pharmacol 10:790-809.

Yuste R, Katz LC (1991) Control of postsynaptic $\mathrm{Ca}^{2+}$ influx in developing neocortex by excitatory and inhibitory neurotransmitters. Neuron 6:333-344.

Zhou N, Parks TN (1992) Developmental changes in the effects of drugs acting at NMDA or non-NMDA receptors on synaptic transmission in the chick cochlear nucleus (Nuc magnocellularis). Dev Brain Res 67:145-152. 